\title{
A review of squeaking in ceramic total hip prostheses
}

\author{
Ehsan Askari ${ }^{\mathrm{a}, *}$, Paulo Flores ${ }^{\mathrm{b}}$, Danè Dabirrahmani ${ }^{\mathrm{a}}$, Richard Appleyard ${ }^{\mathrm{a}}$ \\ a Australian School of Advanced Medicine, Macquarie University, Sydney, Australia \\ b Department of Mechanical Engineering, School of Engineering, University of Minho, Portugal
}

\section{A R T I C L E I N F O}

\section{Article history:}

Received 29 May 2015

Received in revised form 28 August 2015

Accepted 10 September 2015

Available online 25 September 2015

\section{Keywords:}

Ceramic total hip arthroplasty

Squeaking

Fluid-film lubrication

Friction

Multibody dynamics methodology

Complex eigenvalue method

\begin{abstract}
A B S T R A C T
The occurrence of audible squeaking in some patients with ceramic-on-ceramic ( $\mathrm{CoC}$ ) hip prostheses is a cause for concern. Great effort has been dedicated to understand the mechanics of the hip squeaking to gain a deeper insight into factors contributing to sound emission from $\mathrm{CoC}$ hip articulation. Disruption of fluid-film lubrication and friction were reported as the main potential cause, while patient and surgical factors, and design and material of hip implants, were also identified as leading factors. This article summarizes the recent available literature on this subject to provide a platform for future research and development. Moreover, high wear rates and ceramic liner fracture as viable consequences of hip squeaking are discussed.
\end{abstract}

(c) 2015 Elsevier Ltd. All rights reserved.

\section{Introduction}

The natural hip articulation is one of the greatest natural engineering designs to exist inside the body, Fig. 1. While supporting the entire weight of the body, the hip joint provides a stable and smooth articulation of the lower limb. Although the natural hip joint may provide a lifetime of mobility without any serious problem, chronic pain and disease can affect the hip joint leading to pain and restricted movement. Often affected hip joints are replaced with a biomaterial total hip arthroplasty (THA), Fig. 2. THA restores the physical functioning of the hip joint and reduces pain in most patients, thus improving their social wellbeing and quality of life [1].

The mechanism of THA constitutes a femoral stem fixed in the intramedullary canal of the femur and a ball fixed to the femoral neck of the stem, which articulates in a cup embedded in the acetabular of pelvis, shown in Fig. 3. All components of hip arthroplasty are made of biocompatible materials and biofunctional solutions. The femoral components including the femoral stem and neck are generally made of stainless steel, cobalt-based alloy or titanium-based alloy, while the femoral head is either metal or ceramic. The cup backing can be made of metal or plastic depending on its function. The former used with a plastic cup to secure its fixation to the pelvic bone, whereas the plastic backing is utilized with metal or ceramic cup for absorbing dynamic loads. The most common materials used for bearing surfaces are listed in

\footnotetext{
* Corresponding author. Tel.: +61 416073601.

E-mail address: ehsanaskary@gmail.com (E. Askari).
}

Table 1 [3]. The mechanical properties and typical roughness values $R_{a}$ of the above materials are reported in Table $2[3,4]$.

THA has revolutionised the treatment of osteoarthritis (degenerative joint diseases), bone tumours, traumas and rheumatoid arthritis. More than 38,000, 80,000 and 200,000 THA procedures are performed annually in Australia, UK and US, respectively with a survival rate of $85-87 \%$ after 25 years [5-8]. Due to the difficulty of revision THA and the trauma to patients, it is critical, especially for younger population, that the longevity of the hip implant becomes maximized [9].

Since the early artificial hip joints, around the 1960s, the most used combination is a metal head on a plastic cup (MoP). MoP and ceramic-on-plastic (CoP), also denoted as soft on hard couples, are known to suffer from wear of the plastic part with resultant debris causing osteolysis. In order to reduce the wear rate, alternative hard-on-hard material combinations have been promoted, such as metal-on-metal (MoM) and ceramic-on-ceramic (CoC). However, the presence of potentially cancerous metal ions, developed from wear particles is a serious issue with MoM hip implants [10]. The first CoC bearing was implanted by Pierre Boutin in 1970 [11] in the form of an alumina ceramic ball glued to a metal stem that was cemented in the femur. Alumina ceramic bearings are one of most promising artificial hip joints due to their biocompatibility, high hardness, perfect chemical inertia and low coefficient of friction $[12,13]$. From the reliability point of view, it has been suggested that surgeons, faced with young and active patients, should consider ceramics as the only safe hard-on-hard bearing surface [14-16]. 


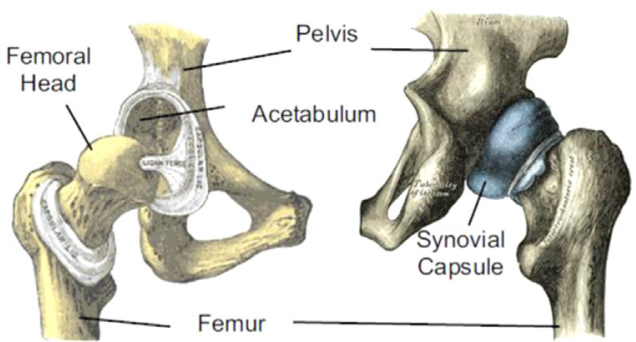

Fig. 1. Anatomy of the hip joint-left: "dissected" joint, right: synovial capsule (adapted from Gray's Anatomy tables) [2].

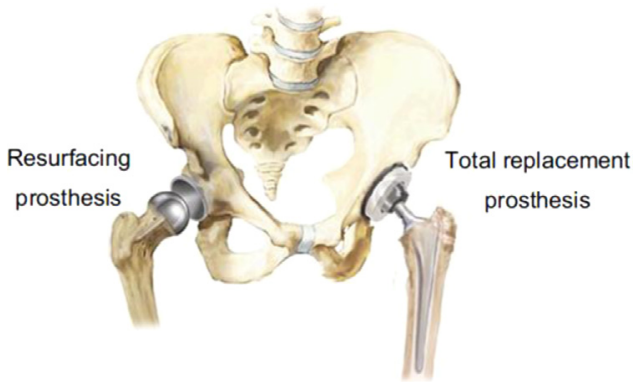

Fig. 2. Total replacement and resurfacing hip prostheses [2].

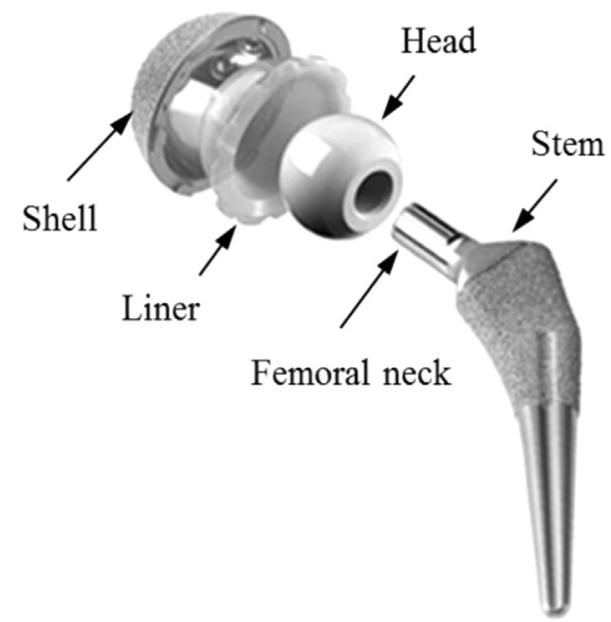

Fig. 3. Main components of an artificial hip joint [2].

Table 1

The most common materials for artificial hip joints [3].

\begin{tabular}{ll}
\hline Head & M: stainless steel, $\mathrm{CoCr}$ and $\mathrm{CoCrMo}$ alloy C: alumina and zirconia \\
Cup & P: UHMWPEM: $\mathrm{CoCr}$ and CoCrMo alloy C: alumina \\
\hline
\end{tabular}

M: metal; C: ceramic; P: plastic.

Table 2

Mechanical properties of materials and typical roughness values for hip implant components: Young's modulus $E$, Poisson's ratio $v$, average roughness $R_{a}[3,4]$.

\begin{tabular}{lllll}
\hline Material & & $\boldsymbol{E}(\mathbf{G P a})$ & $\boldsymbol{v}$ & $\boldsymbol{R}_{\boldsymbol{a}}(\boldsymbol{\mu} \mathbf{m})$ \\
\hline $\mathrm{P}$ & UHMWPE & 1 & 0.4 & $0.1-2.5$ \\
$\mathrm{M}$ & Stainless steel & 210 & 0.3 & $0.01-0.05$ \\
& CoCrMo & 230 & & \\
$\mathrm{C}$ & Alumina & 380 & 0.3 & 0.001 \\
& Zirconia & 210 & & \\
\hline
\end{tabular}

The occurrence of squeaking has however been discussed recently as a cause for concern in THA with CoC bearings [17,18]. From an engineering point of view, squeaking has been associated with friction as the femoral head and cup articulate [19]. However, hip squeaking is multifactorial and important additional factors which may contribute to hip squeaking include: (i) design and materials; (ii) implant position and orientation; (iii) patient factors; and (iv) disruption of fluid-film lubrication and friction. While significant research has been undertaken toward understanding of the mechanism of squeaking, the origins and causes of squeaking still need more investigations. Furthermore, consequences of hip squeaking are unknown and it is not certain if unrevised squeaking hips will result in a clinically adverse outcome to the patient. To date, it has been suggested that high wear rates in artificial hip joints may be associated with hip squeaking [20-22]. It is known that wear of bearing surfaces is a crucial factor in primary failure of all artificial hip joints, influencing their lifetime and performance [23-25]. The intention of this review paper, therefore, is to report the most outstanding work associated with the potential causes and consequences of hip squeaking.

This paper is organized as follows. In Section 2, after defining hip squeaking, a brief description of hip squeaking is provided. The potential factors contributing to hip squeaking are classified into four main groups, namely: (i) design and material; (ii) implant position and orientation; (iii) patient factors; and (iv) disruption of fluid-film lubrication and friction. It has been explained that how these factors affect hip squeaking. Fundamental issues associated with fluid-film lubrication are described, before discussing the disruption of fluid-film lubrication and friction which are main reasons of hip squeaking from an engineering point of view. It is in turn reported that hip squeaking is associated with high wear rates of noisy hips compared to silent hips and ceramic liner fracture. Table 3 summarizes factors linked to hip squeaking by available literature. In Section 3, a comparison of unstable frequencies obtained from clinical data, experimental and computational analyses is presented. Furthermore, the finite element method and multibody methodology as computational approaches for investigation of hip squeaking phenomenon are discussed. Finally, discussing future research directions in this field forms the fourth section of the present article.

\section{Hip squeaking}

While CoC THA has demonstrated very good clinical performance due to the superior wear resistance and low biological reactivity, the occurrence of audible squeaking in some patients is a cause for concern. Squeaking is defined as an audible sound, 20$20,000 \mathrm{~Hz}$, that occurs during movement of the hip joint, which was firstly described in 1950s [26]. In-vitro, squeaking was also reported by Charnley [27] during the friction analysis of this bearing couple. In fact, hip squeaking has been reported with a wide prevalence rate of $1-24.6 \%$ [14,17,18,28-42]. However, it has been reported that no evidence of squeaking observed in their cohort of patients and only eight of patients (6.4\%) underwent grinding and clicking noises [37]. In vivo, CoC fundamental squeaking frequencies have been reported in the range of $400-7500 \mathrm{~Hz}$ [43]. A spectral view and a fast Fourier transform of squeaking hips analysed in vivo have also been illustrated in Fig. 4. The onset of squeaking was also revealed 14-40 months after total hip arthroplasty surgery [29,38,44-46].

It is worth noting that $15 \%$ of squeaking hips stopped emitting noise after a mean follow up of 9.5 years [46]. It has been reported that thirteen squeaker hips out of fourteen stopped squeaking at the last follow up, which its duration was 69.5 months [30], indicating that it could be a temporary pattern. There was no significant difference in patient satisfaction between those with squeaking and silent hips, which showed that squeaking is usually well-tolerated by patients [46]. Furthermore, squeaking is not 
Table 3

Studies demonstrating factors associated with hip squeaking.

\begin{tabular}{|c|c|c|c|}
\hline Authors & Study type & Significant association & No association \\
\hline Kang [87] & Mechanical study & $\begin{array}{l}\text { Negative friction-velocity slope, clearance, material } \\
\text { stiffness }\end{array}$ & \\
\hline Weiss et al. [115] & Mechanical study & $\begin{array}{l}\text { Friction, the level of load magnitude, bearing kine- } \\
\text { matics, system damping }\end{array}$ & \\
\hline Askari et al. [105] & Mechanical study & $\begin{array}{l}\text { Stick-slip friction, negative friction-velocity slope, con- } \\
\text { tact force changes }\end{array}$ & Sprag-slip \\
\hline Owen et al. [38] & Clinical study & & Height, weight, BMI, age, indication \\
\hline Owen et al. [39] & Meta-analysis & Stryker Accolade femoral stem & \\
\hline Brockett et al. [83] & Mechanical study & Friction, third body particle, bearing clearance. & \\
\hline $\begin{array}{l}\text { Dacheux et al. } \\
\text { [149] }\end{array}$ & Case report & Ceramic fracture & \\
\hline Fan et al. [66] & Mechanical study & Femoral stem design, friction & \\
\hline Hothan et al. [73] & Mechanical study & & The head-taper interface \\
\hline Kiyama et al. [36] & Clinical study & $\begin{array}{l}\text { Age, obesity, cup lateralisation, Accolade stem, shor- } \\
\text { tened head length, activity level, pain, satisfaction }\end{array}$ & Loosening \\
\hline $\begin{array}{l}\text { McDonnell et al. } \\
\text { [42] }\end{array}$ & Clinical study & $\begin{array}{l}\text { Range of motion, inclination, anteversion, head size, } \\
\text { ligament laxity }\end{array}$ & Age, height, weight, BMI, gender, satisfaction, stem type \\
\hline Askari et al. [150] & Mechanical study & Stick-slip friction, negative friction-velocity slope & \\
\hline Weiss et al. [19] & Mechanical study & $\begin{array}{l}\text { Friction-induced flutter instability (whirl), the femoral } \\
\text { stem }\end{array}$ & \\
\hline Sarialli et al. [85] & $\begin{array}{l}\text { Mechanical-clinical } \\
\text { study }\end{array}$ & $\begin{array}{l}\text { Edge loading, third body particle, friction, type of } \\
\text { motion activity }\end{array}$ & \\
\hline Fan and Chen [113] & Mechanical study & $\begin{array}{l}\text { A torsional vibration and a flexural vibration of the } \\
\text { femoral component }\end{array}$ & Acetabular component \\
\hline Sander et al. [84] & Mechanical study & $\begin{array}{l}\text { Edge loading, the right combination of load vector and } \\
\text { bearing surface conditions, (abduction and contact } \\
\text { force) }\end{array}$ & \\
\hline $\begin{array}{l}\text { Chevillotte et al. } \\
\text { [151] }\end{array}$ & Clinical study & $\begin{array}{l}\text { Trident acetabular cup, anteversion, Metal transfer, } \\
\text { stripe wear }\end{array}$ & Age, gender, height, weight \\
\hline Buttaro et al. [152] & Clinical study & & Hip implant design \\
\hline $\begin{array}{l}\text { Chevillotte et al. } \\
\text { [55] }\end{array}$ & Clinical study & Gender, weight, height, activity level, & Age, BMI, neck length, HHS \\
\hline Haq et al. [35] & Clinical study & BMI, acetabular opening angle, limb length shortening & Age, acetabular anteversion \\
\hline Kuo et al. [37] & Clinical study & Age, head size, range of motion & $\begin{array}{l}\text { Gender, height, weight, BMI, cup size, quality of life, neck length, } \\
\text { inclination }\end{array}$ \\
\hline Sexton et al. [46] & Clinical study & $\begin{array}{l}\text { Height, weight, age, femoral offset, inclination, ante- } \\
\text { version, medialisation }\end{array}$ & Femoral head size, patient satisfaction, BMI, HHS (Harris hip score) \\
\hline Hothan et al. [57] & Mechanical study & Stem design, assembled stem, axial load & Cup design, bearing clearance \\
\hline Hothan et al. [69] & Mechanical study & & Cup design, assembled cup \\
\hline Fan et al. [112] & Mechanical study & $\begin{array}{l}\text { Friction-induced vibration due to mode-coupling, the } \\
\text { femoral stem, neck and head }\end{array}$ & Ceramic insert \\
\hline Bernasek et al. [50] & Clinical study & Gender, inclination & \\
\hline Choi et al. [54] & Clinical study & Head size, gender & Age, height, weight, BMI, cup size, neck length, abduction \\
\hline Cogan et al. [33] & Clinical study & Association between noise and dissatisfaction & Age, height, weight, BMI, alumina insert thickness \\
\hline Ki et al. [30] & Clinical study & BMI (body mass index), cup design (Osteonics cup) & Inclination, anteversion, \\
\hline Parvizi et al. [18] & Clinical study & $\begin{array}{l}\text { Neck impingement, Trident acetabular cup, combina- } \\
\text { tion of Trident acetabular component and Accolade } \\
\text { stem }\end{array}$ & \\
\hline Kang [114] & Mechanical study & $\begin{array}{l}\text { Negative friction-velocity slope, the femoral stem, } \\
\text { bearing stiffness, bearing kinematics, head size, the } \\
\text { level of load magnitude }\end{array}$ & \\
\hline Currier et al. [110] & Mechanical study & $\begin{array}{l}\text { Stick-slip phenomenon, bearing clearance, friction, hip } \\
\text { joint velocity }\end{array}$ & Joint load magnitude, individual components \\
\hline Sariali et al. [103] & Mechanical study & & Micro-separation \\
\hline Sariali et al. [153] & Mechanical study & Third body particle, high friction, stick-slip & Edge loading, abduction \\
\hline Weiss et al. [49] & Mechanical study & $\begin{array}{l}\text { Self-excited vibrations, high friction, the femoral stem } \\
\text { and neck }\end{array}$ & \\
\hline Glaser et al. [88] & $\begin{array}{l}\text { Mechanical-clinical } \\
\text { study }\end{array}$ & Micro-separation & \\
\hline $\begin{array}{l}\text { Chevillotte et al. } \\
\text { [61] }\end{array}$ & Mechanical study & $\begin{array}{l}\text { Material transfer condition, disruption of fluid } \\
\text { lubrication }\end{array}$ & Stripe wear, edge loading, microfracture, joint load magnitude \\
\hline Mai et al. [31] & Clinical study & $\begin{array}{l}\text { Height, neck geometry, V40 neck/Trident combination } \\
\text { and C-taper/Trident combination }\end{array}$ & $\begin{array}{l}\text { Age, gender, weight, BMI, indication, head size, acetabular } \\
\text { component }\end{array}$ \\
\hline $\begin{array}{l}\text { Esposito et al. } \\
\text { [154] }\end{array}$ & Clinical study & Type of motion activity & Inclination, patient satisfaction \\
\hline \multirow[t]{2}{*}{ Restrepo et al. [52] } & Clinical study & & \\
\hline & Accolade stem & $\begin{array}{l}\text { Age, height, weight, BMI, abduction, anteversion, med- } \\
\text { icalisation, femoral offset }\end{array}$ & \\
\hline Restrepo et al. [64] & Clinical study & Type of motion activity & Pain, functional impairment, ceramic fracture \\
\hline Swanson et al. [44] & Clinical study & $\begin{array}{l}\text { Stryker Trident cup/accolade stem combination, short } \\
\text { femoral neck length, rheumatoid arthritis }\end{array}$ & $\begin{array}{l}\text { Age, sex, height, activity level, acetabular component size, femoral } \\
\text { head size, BMI, laterality, femoral offset, inclination }\end{array}$ \\
\hline Jarrett et al. [56] & Clinical study & Negative quality of life & $\begin{array}{l}\text { Inclination, anteversion, leg length, pain, pattern of activity (type of } \\
\text { motion activity) }\end{array}$ \\
\hline Restrepo et al. [17] & Clinical study & $\begin{array}{l}\text { Edge loading, stripe wear, the kinematics of the hip } \\
\text { implant }\end{array}$ & \\
\hline
\end{tabular}


Table 3 (continued)

\begin{tabular}{|c|c|c|c|}
\hline $\begin{array}{l}\text { Keurentjes et al. } \\
\text { [29] }\end{array}$ & Clinical study & Short neck length & $\begin{array}{l}\text { impingement, age, height, weight loosening, osteolysis } \\
\text { Inclination, anteversion, age, gender, BMI, cup size, head size, stem } \\
\text { size }\end{array}$ \\
\hline Walter et al. [43] & Clinical study & $\begin{array}{l}\text { Height, weight, age, edge loading, titanium shells, } \\
\text { metallic femoral components, a stiffness mismatch } \\
\text { between the shell and liner }\end{array}$ & Ceramic components, bearing clearance \\
\hline Brockett et al. [71] & Mechanical study & Bearing clearance, friction & \\
\hline Murphy et al. [41] & Clinical study & & Osteolysis, loosening \\
\hline Walter et al. [45] & Clinical study & $\begin{array}{l}\text { Height, weight, age, anteversion, inclination, impinge- } \\
\text { ment, edge loading }\end{array}$ & \\
\hline Taylor et al. [89] & Clinical study & stripe wear, edge loading, impingement, inclination & \\
\hline Jarrett et al. [28] & Clinical study & & Pain, anteversion, cup position \\
\hline Morlock et al. [58] & A case report & $\begin{array}{l}\text { Mismatch between the joint bearings, a couple of zir- } \\
\text { conium oxide and aluminium oxide }\end{array}$ & \\
\hline
\end{tabular}

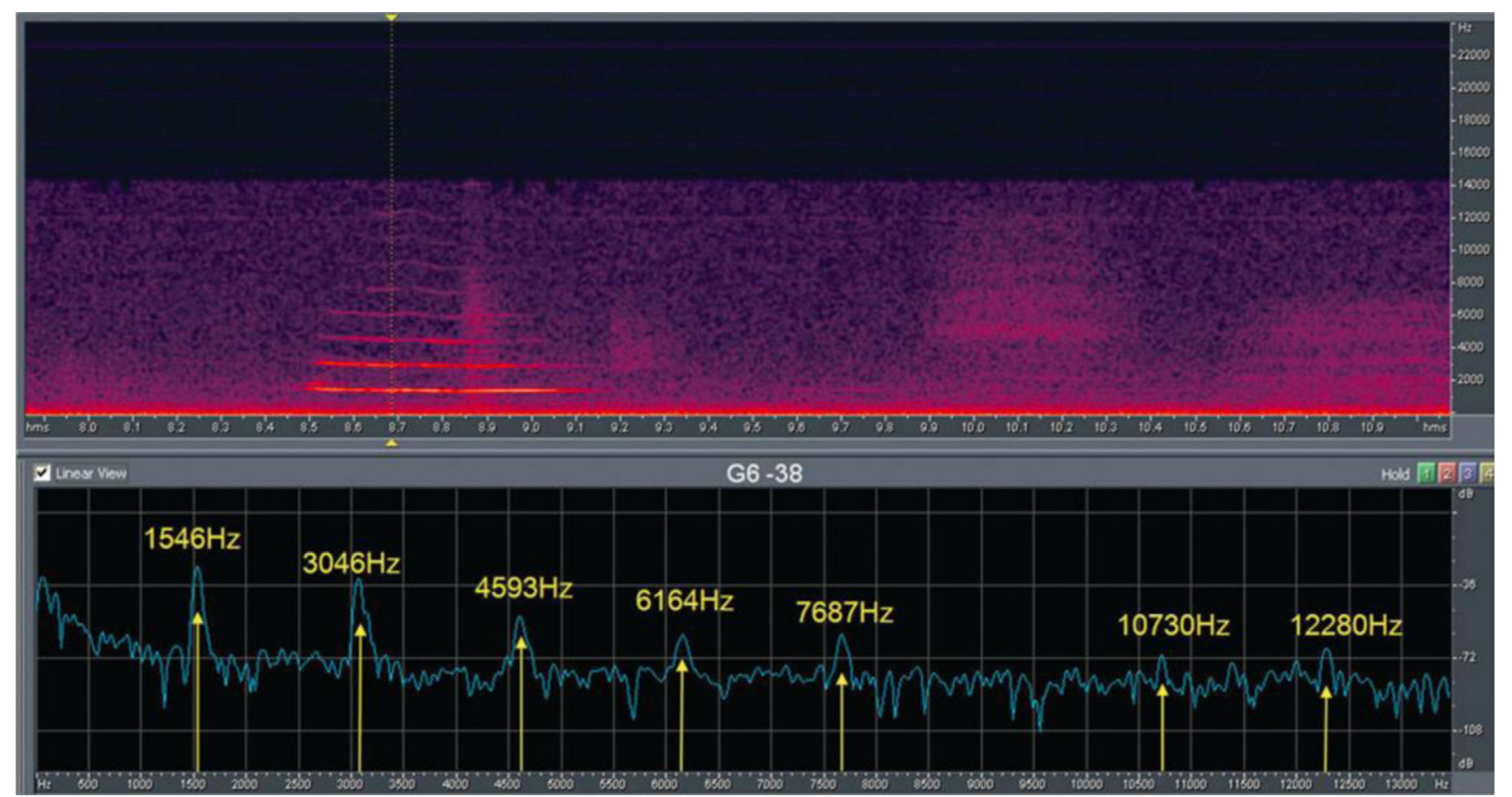

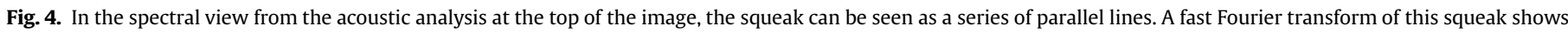
a harmonic series of frequency peaks with a fundamental at $1546 \mathrm{~Hz}$ [43].

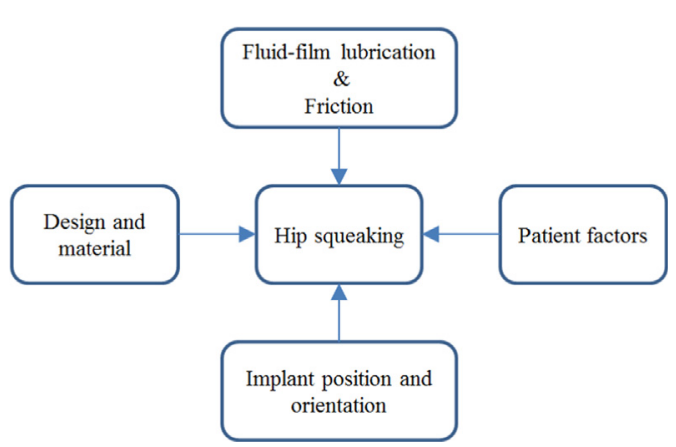

Fig. 5. Diagram showing proposed mechanisms and associations of squeaking in ceramic-on-ceramic total hip replacements.

usually associated with pain, instability and limited hip function $[17,41,44,45,47]$. Squeaking may be persistent, but more often it is intermittent and tolerable. In some cases, the noise can be avoided by activity modification alone. The incidence rate of revision for squeaking alone is also significantly low, $0.2-0.48 \%[39,45]$.
Pain, limited function, acetabular component positioning, intervention, abduction, femoral head size, type of femoral stem, impingement, age, height, weight loosening, osteolysis size Ceramic components, bearing clearance

\section{Osteolysis, loosening}

Pain, anteversion, cup position 


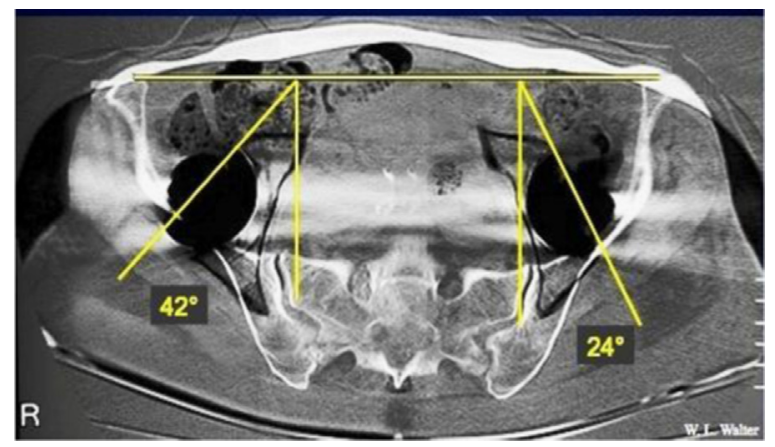

Fig. 6. A computed tomography scan of bilateral ABG II ceramic-on-ceramic hip replacements, the right hip had excessive acetabular anteversion and it squeaked with walking. The left hip with ideal anteversion did not squeak [45].

and increased wear, which could in turn induce squeaking [45,51]. Interestingly, one study revealed that a hip is 29 times more likely to squeak when the acetabular component is positioned out of a defined range [45]. In general, although acetabular component orientation and position were correlated with squeaking, squeaking can also occur when the acetabular component is in the ideal range demonstrating that cup orientation is not the only factor causing hips to squeak [45]. On the other hand, a good number of studies illustrated that there was no direct correlation between the acetabular component position and squeaking [17,52] including anteversion and inclination [17] and femoral offset and stem position $[44,52]$.

\subsection{Patient factors}

Patient factors, such as age, sex, height and weight, can also influence squeaking $[45,46]$. Taller, heavier and younger patients with higher levels of activity are significantly more likely to have hips that squeak $[36,45,46,53]$. Although prevalence of squeaking was also found to be associated with obesity and BMI (body mass index) $[30,35,36]$, Sexton and co-workers reported that they were not associated with audible vibration of THA [46].

Squeaking was also seen more commonly when patients exhibited limb length shortening and rheumatoid arthritis [35,44]. Another patient factor which can be correlated with a higher risk of squeaking is gender. It has been reported that female patients are more prone to squeaking [50], although a number of studies showed it is more frequent in men [54,55]. Interestingly, two cohorts of patients with squeaking $\mathrm{CoC}$ hips showed no correlation with age, sex, height, activity level and BMI [29,44]. Furthermore, it was seen that squeaking occurs more in walking, bending, rising and stair-climbing $[17,40,45,46,56]$. Finally, squeaking is not usually associated with pain, instability and limited hip function $[17,41,44,45,47]$.

\subsection{Design and material}

Prosthetic design and bearing materials are contributing factors to the prevalence of squeaking [18,44,52,57-59]. Although all types of bearing surfaces exhibit various noises, squeaking has only been described with hard-on-hard bearings [28]. One of the first studies on hip squeaking illustrated that the mismatch of a zirconium head against aluminium cup was associated with hip squeaking and higher surface damage [58]. On the acetabular side, several authors have noted an increased rate of squeaking in the Stryker Trident inserts which has an elevated metal rim, Fig. 7 $[18,31,44]$. This unique design was proposed to provide protection of the brittle ceramic insert from neck impingement and the material strength increase of the insert $[44,59]$. This protective

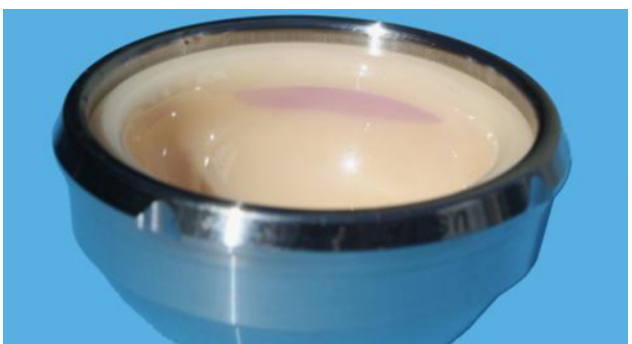

Fig. 7. A Trident (Stryker Orthopaedics, Mahwah, New Jersey), metal-backed ceramic liner with an elevated rim [21].

rim, however, decreased range of motion by $10-15^{\circ}$ [60], leading to metal against metal contact due to neck-rim impingement, Fig. 8, which generates particulate metal debris in the articular surface leading to the disruption of fluid-film lubrication and consequently squeaking [44,61]. Furthermore, the neck-rim impingement also increased the chance of lever out, edgeloading and stripe wear resulting in further damage onto articulating surfaces and squeaking [17,60-63].

The Stryker Accolade femoral stem has a unique V-40 neck design which leads to less impingement according to its smaller neck diameter. Moreover, the titanium-molybdenum-zirconiumiron stem is $25-40 \%$ more flexible than that of titanium-aluminium-vanadium [44]. Consequently, these characteristics lead to lower bending stiffness and therefore lower fundamental frequency of the femoral stem, making it more capable of amplifying vibrations generated by hip articulation [44, 64]. Patients with the titanium-molybdenum-zirconium-iron-alloy stem were seven times more likely to undergo squeaking than those with the titanium-aluminium-vanadium-alloy stem [44,52]. After vibrational tests of different hip implant designs, it was confirmed that stem design significantly increased the incidence of hip squeaking, amplifying vibration resulting from a stick-slip mechanism or friction-induced vibration [57,65]. Fan and co-authors reported that shorter, heavier or stiffer stems might limit the possibility of squeaking [66]. A few study also reported higher incidence of squeaking with the Trident cup and Stryker Accolade femoral stem combination than the Stryker Trident cup with other types of femoral stem $[18,64]$.

Short neck length results in smaller range of motion and thus neck-rim impingement due to the tapered nature of the femoral stem [29]. It can also result in soft tissue laxity which can lead to stripe wear and micro-separation and therefore be a precursor of the squeaking sound $[29,44,67,68]$. The acetabular component size and femoral head size did not directly correlate with hip squeaking $[44,46,69]$. However, larger diameter ceramic bearings showed higher friction factors, which could make them more susceptible to produce noises than smaller diameter bearings [70]. Moreover, although cup design and the bearing clearance did not show any influence on the dynamic behaviour of the system [69], bearing clearance can affect the lubrication and friction in the bearing articulation [71,72] and the design of the cup can influence the risk of metal transfer and subluxation, leading to squeaking [57]. In addition, a recent study reported that squeaking vibration was not influenced by the head-taper interface [73].

One assumption about squeaking is that it is due directly to independent vibration and natural frequencies of either acetabular or femoral components of the THA, which are correlated with implant design and materials. Although the fundamental frequencies of the metal shells alone ranged from $4.3 \mathrm{kHz}$ to $9.2 \mathrm{kHz}$, eigenfrequencies of the assembled cup shells after inserting ceramic inlay are above $16 \mathrm{kHz}[43,69]$. Moreover, natural frequencies of the ceramic femoral head are above the audible human range. These theories can consequently not account for the 

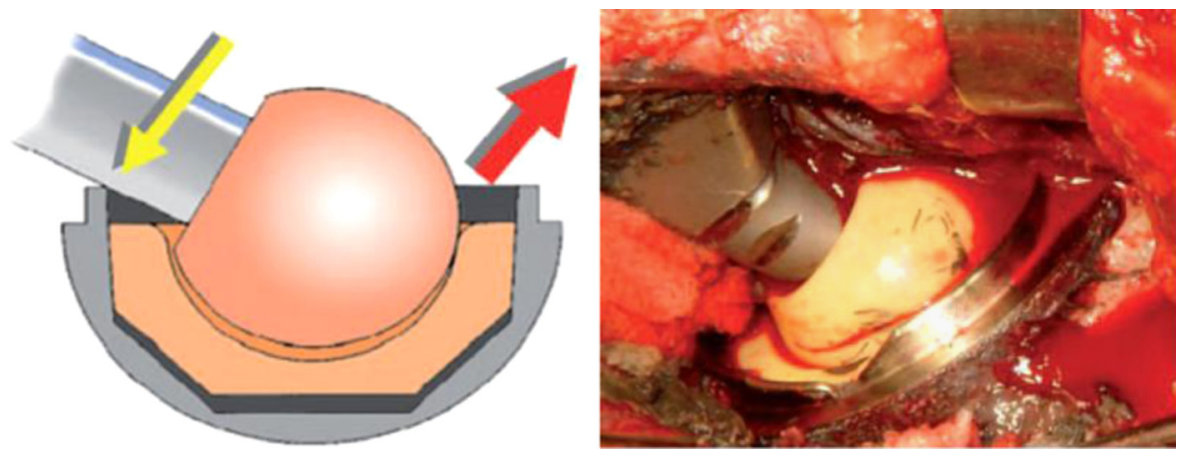

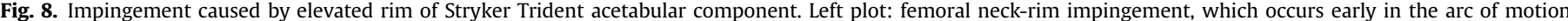

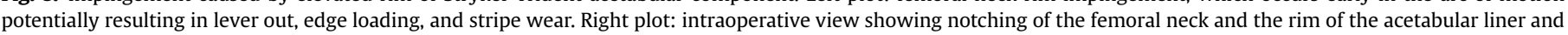
the elevated rim, [44].

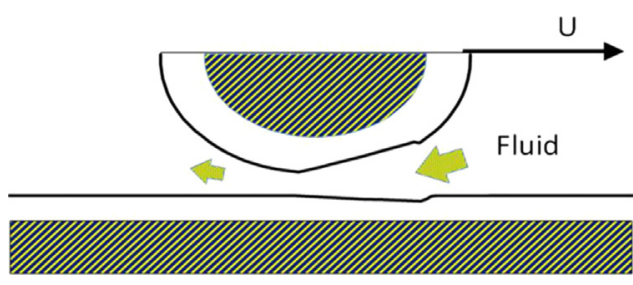

Fig. 9. Schematic of fluid entrainment [76].

observed squeaking $[43,69]$. However, the vibration frequencies of titanium femoral stem are in the range of $2-20 \mathrm{kHz}$ [43] which are within the audible human range and can contribute to squeaking.

\subsection{Fluid-film lubrication and friction}

Since the synovial capsule is preserved in THA, the hip implant is lubricated. However, the fluid in this case is more similar to that obtained from diseased joints, which differs from healthy synovial fluid. The characteristics of these fluids are close to the normal bovine serum, which is diluted at $25 \%$ indicated in the ISO, which is often used as lubricant for hip implant tests. While these fluids are non-Newtonian and demonstrate piezo-viscosity [74], generally a simple incompressible, Newtonian, isoviscous lubricant model can be assumed. As previously mentioned, squeaking noises are associated with the articulation of the femoral head and cup from an engineering point of view. In what follows, the mechanics of fluid-film lubrication in artificial hip joints is firstly described. In turn, the disruption of fluid-film lubrication and friction are introduced as main causes for hip squeaking.

\subsubsection{Fluid-film lubrication}

Fluid film lubrication occurs when there is a continuous fluid film separating articulating components. The fluid film thickness must be wider than the average surface roughness to avoid surface asperity interaction and the associated high friction and wear. Fluid film lubrication can be theoretically described by Reynolds' equation, including both the entraining and squeeze film actions. Fluid entrainment occurs when the relative motion between bearing surfaces drags the fluid into the space constituted between them which may separate the articulating surfaces, as observed in Fig. 9.

The relationship among variables affecting minimum film thickness has been demonstrated in the Hamrock and Dowson formula [75]

$h_{\min }=2.789 R\left\{\frac{\eta u}{\frac{A}{e}}\right\}^{0.65}\left\{\frac{w}{\hat{A}_{R^{2}}}\right\}^{-0.21}$

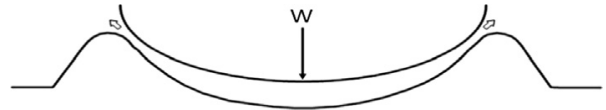

Fig. 10. Schematic of squeeze film formation for a cylinder on a soft flat layer [76].

in which $R$ is equivalent radius of bearing, Eq. (3), $\eta$ the viscosity of lubricant, $u$ is sliding velocity, $w$ load and $e^{A}$ the equivalent material stiffness, Eq. (4). The equivalent radius of the bearing is defined as the product of the radius of the two surfaces in contact divided by their difference. Consequently, the less clearance/more refined manufacturing tolerances, the more the equivalent radius of the bearing.

Squeeze film lubrication effect occurs when separated surfaces move towards each other very quickly, as illustrated in Fig. 10. The pools of lubricant may be trapped by the contact surfaces, which leak out slowly. The relation of variables affecting minimum squeeze film is materialized in following equation [77]:

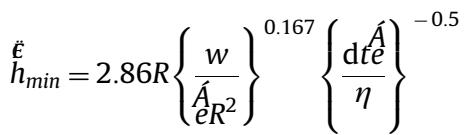

where

$\frac{1}{R}=\frac{1}{R_{1}}-\frac{1}{R_{2}}$

$\frac{1}{\hat{A}}=\frac{1}{2}\left(\frac{1-v_{1}^{2}}{E_{1}}+\frac{1-v_{2}^{2}}{E_{2}}\right)$

in which $R_{1}$ and $R_{2}$ are the head and the cup radii, respectively, and $E_{1}, v_{1}$ and $E_{2}, v_{2}$ denote Young's modulus and Poisson ratio of the head and the cup material, respectively, and $t$ is time variable. Squeeze film formation could occur during walking when heal strikes the ground (heel-strike), Fig. 11, due to ground forces suddenly appeared [78]. During walking, it is feasible that articulating bearings do not come into contact. If, however, the properties of the lubrication break down and the viscosity decreases such as in arthritis, surface contact cannot be longer avoided.

Since the fluid film thickness can be very similar to the average roughness of surfaces articulating, mixed lubrication and boundary lubrication could also take place, even in simple daily activities. In these cases, the bearing surfaces may contact. The lambda ratio $(\lambda)$ is defined to distinguish the type of lubrication regime, as follows:

$\lambda=\frac{h_{\min }}{R_{a}}$

where $h_{\min }$ corresponds to the minimum film thickness and $R_{a}$, 
a

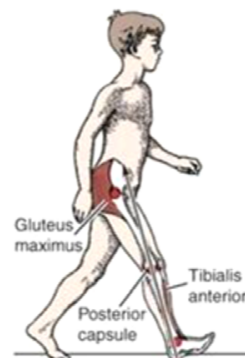

Heel strike

(initial contact) b

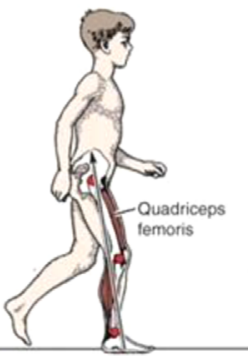

Loading response

(foot flat)
C

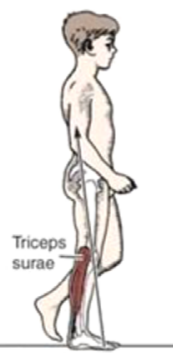

d

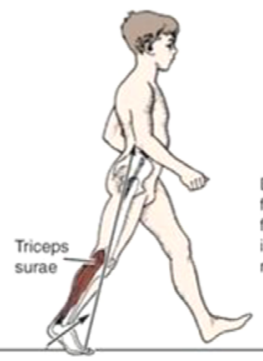

e

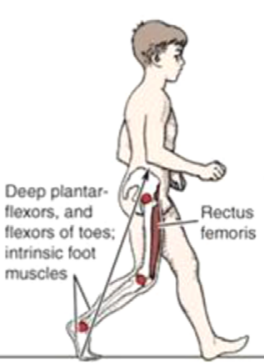

$f$

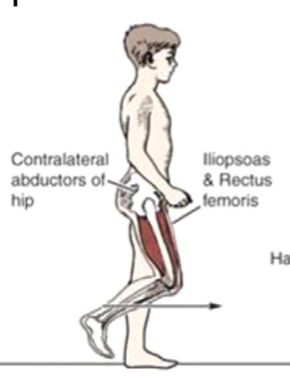

g

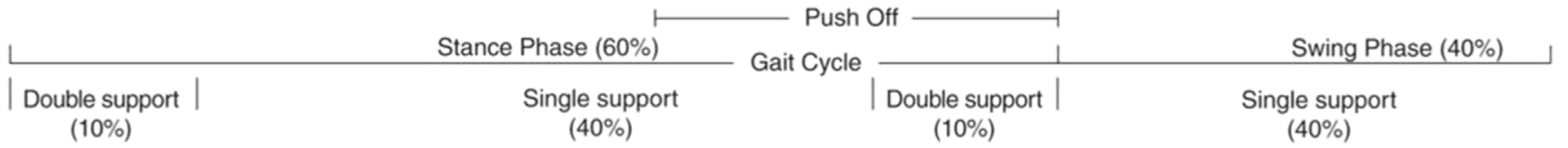

Fig. 11. The gait cycle with the heel strike as the first phase [79].

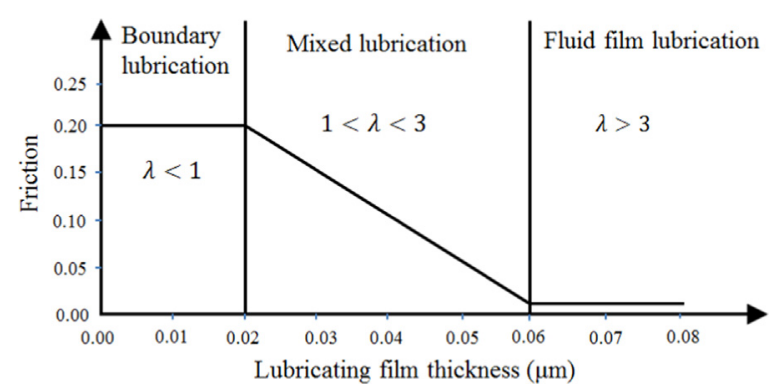

Fig. 12. General relationship between the friction and fluid film thickness [76].

composite roughness of the couple, is

$R_{a}=\sqrt{R_{c}^{2}+R_{h}^{2}}$

Here $R_{c}$ and $R_{h}$ are roughness of the cup and femoral head, respectively. Once the lambda ratio is evaluated, lubrication regime can be identified as illustrated in Fig. 12. Broadly, it can be stated that MoM THA with a roughness of $0.02 \mu \mathrm{m}$ and clearance of $0.04 \mathrm{~mm}$ is mixed lubricated and $\mathrm{CoC}$ THA with a roughness of $0.004 \mu \mathrm{m}$ and clearance of $0.04 \mathrm{~mm}$ is fluid film lubricated $[74,80]$.

\subsubsection{Disrupted fluid-film lubrication}

Many researchers have suggested that $\mathrm{CoC}$ hip squeaking occurs as a result of disruption of fluid film lubrication between bearing surfaces [52,61,81-83]. The fluid film is disrupted by increased surface roughness, particulate metal debris between articulating surfaces, an alteration in the property of synovial fluid and/or abnormal behaviours in prosthetic hip joints such as edge loading and micro-separation. The fluid film is penetrated by large asperities due to high surface roughness and third body particles $[61,81,84,85]$. The fluid-film lubrication regime is converted to either the mixed lubrication or boundary lubrication according to the lambda ratio described in Eq. (5). Moreover, it was reported that increasing the bearing clearance results in reduced fluid film thickness which can also be concluded by Eq. (5), leading to poor lubrication and consequently squeaking [71,83,86,87]. If the property of synovial fluid changes affecting lubricant viscosity, fluid film thickness decreases, which alters fluid lubrication regime and leads to poor fluid lubrication, Eq. (1).

The non-consistent motion, microseparation, rim-neck impingement and edge-loading of THA articulation, prevents the bearing from producing optimum fluid-film lubrication. Nonconformity of bearing surfaces and inadequate fluid film pressure to bear the femoral head loads can result in stripe wear and third body debris
$[61,84,85,88,89]$. Fluoroscopic studies have elucidated microseparation between the ball and cup during daily hip motions [90-93]. Moreover, implants with elevated rims, implant misalignment and small femoral head size are associated with rimneck impingement $[94,95]$. There are also cases of extreme dislocation where the ball exits the socket entirely. Such a dislocation can occur due to neck impingement in which the head is levered out of the cup causing the head to rest upon the socket's rim $[96,97]$. A relatively vertical cup orientation may also cause edge loading [8]. Edge loading was identified as the first step in a chain of events that leads to CoC squeaking and wear [84].

The fluid film lubrication thicknesses described in Eqs. (1) and (2) are obtained for correctly positioned THA. However, these simulations are not appropriate for adverse loading cases such as edge loading. In this case, there are poor lubrication conditions and extreme contact stresses due to the low conformity of the bearing surfaces [98-100]. Maximum contact pressure caused by edge-loading for a CoC hip implant with $36 \mathrm{~mm}$ diameter has been reported as high as $1950 \mathrm{MPa}$ compared to a concentric contact where the pressure was $45 \mathrm{MPa}$ [98]. Moreover, contact pressures for head-liner contact of edge-loaded hard bearings were more than 1 GPa [100]. Edge loading can also cause wear on the surfaces and roughening of both bearing surfaces [84].

While several in vitro studies successfully reproduced squeaking under dry condition $[19,57,61,84]$, it is worth noting that squeaking noises were stopped with adding a small amount of lubricant to a not-lubricated artificial hip articulation [61]. In lubricated conditions, squeaking was replicated by interposing particulate metal debris between the head and liner. Sanders et al. [84] reported that squeaking in lubricated hip prostheses can occur if the right combination of load vector and bearing surface conditions exist such as applying high contact force near the head's wear patch.

\subsection{Friction}

As can be observed from Fig. 12, friction coefficient increases as the lambda ratio decreases. This is the result of increased surface roughness, particulate metal debris between the articulating surfaces, lower synovial fluid viscosity, increased bearing clearance and abnormal motion behaviour of hip implant components. Generally, coefficient of friction in $\mathrm{CoC}$ hip devices is in the range of $0.04-0.13$ [80,101-103]. Nassutt and colleagues [101] reported a coefficient of friction varying from 0.104 for no resting duration up to 0.131 for resting duration of $60 \mathrm{~s}$. This increase in coefficient of friction after rest is due to loss of fluid film lubrication and 
subsequent surface to surface contact when the relative velocity between the bearing surfaces is reduced. This effect tends to make a $\mathrm{CoC}$ hip bearing couple act more like non-lubricated bearings $[101,102]$.

It is known that when two surfaces slide against each other, friction develops and acts as a resistance to relative motion. Sliding is an unsteady phenomenon made up of continuous or transient contact resulting in intermittent or cyclical squeaking due to a slight variation in the normal contact load for instance [104-106]. Moreover, frictional force acts like a cross-coupling force linking normal and parallel motions at the contact surface [107]. It is well known that friction can induce vibration in structures owing to instability in the structural system such as the instability due to a surface property for which friction decreases as relative velocity between sliding surfaces increases [48,104,105]. Moreover, there are other sources of instability in structure systems, namely modecoupling, Sprag-slip, frictional follower forces, stick-slip and material nonlinearity that have all been suggested as possible causes of self-excited friction induced vibration [48,104,105,107109]. Mode coupling instability is characteristic that frequencies of two structural modes of a system come closer together until they merge and result in a pair of an unstable and a stable mode. The stick-slip exists in most of friction-induced vibration problems as static friction is greater than dynamic friction. Sprag-slip instability is usually characterized by jumping or violation of the system parameters such as contact force and penetration depth during the gait cycle. As friction force follows the displacement during sliding of contacting bodies, it acts as follower force which is a type of instability in the system. Follower forces are well known sources of asymmetry in stiffness matrices and are considered to be responsible for flutter instabilities in a wide variety of mechanical systems. Another type of instability in a system is due to nonlinear stiffness of articulating components, the femoral head and the liner, leading to nonlinear normal contact force.
A possible cause of squeaking in MoM and $\mathrm{CoC}$ bearings without lubrication is the stick-slip phenomenon between the head and cup surfaces $[110,111]$. It has been computationally and experimentally shown that friction-induced vibration is the main reason of hip squeaking $[48,49]$. In order to consider this issue numerically, a complex eigenvalue method was employed to identify the stability properties of hip implants under laboratory conditions and in a pseudo-in-vivo configuration. However, considerable differences between theoretical and in-vivo results were observed, which could be associated with the choice of boundary conditions [112,113]. These investigations also reported that hip prostheses become unstable when the friction coefficient between components reaches critical values. It was observed that increasing the critical friction coefficient could decrease the occurrence of ceramic bearing squeaking $[112,113]$.

In a theoretical model of a sphere attached to a rotating flexible beam, as a simple model of THA, the bending modes of the beam produced by the dynamic instability under the negative frictionvelocity slope was identified as the cause of squeaking [87,114]. An experimental study found that a friction induced whirl vibration led to oscillation behaviour on top of the gross head movement against the liner [19]. This was a micrometre scale elliptical motion inside the liner and the vibrational pattern of hip implants was two-dimensional. However, the hip squeaking frequencies they reported were higher than those found in-vivo. A computational investigation on nonlinear vibration and dynamic behaviour of a CoC hip implant demonstrated that the femoral head had a micometer/nanometre motion inside the liner [105], illustrated in Fig. 13. This study took the physiological three-dimensional rotation angles and forces into account and found that the vibration of an artificial hip joint had a three-dimensional characteristic. The reported cause of hip squeaking was friction-induced vibration owing to different phenomena such as stick-slip friction, negativesloping friction and contact force changes. Moreover, frictioninduced vibration can increase the sliding distance of the contact a

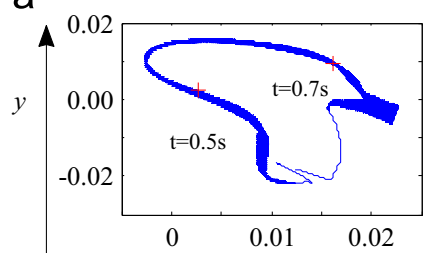

$b$
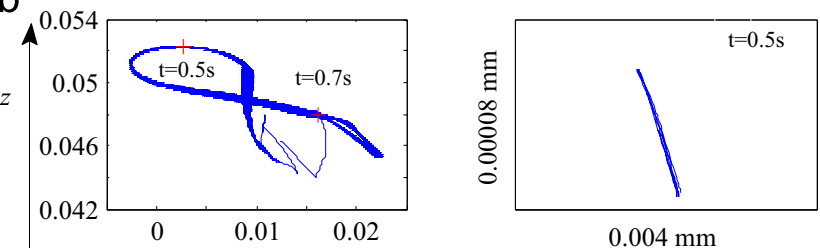

$0.004 \mathrm{~mm}$

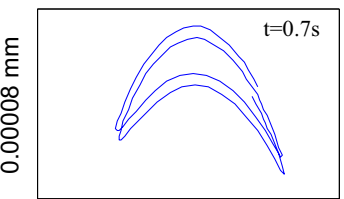

$0.004 \mathrm{~mm}$

C
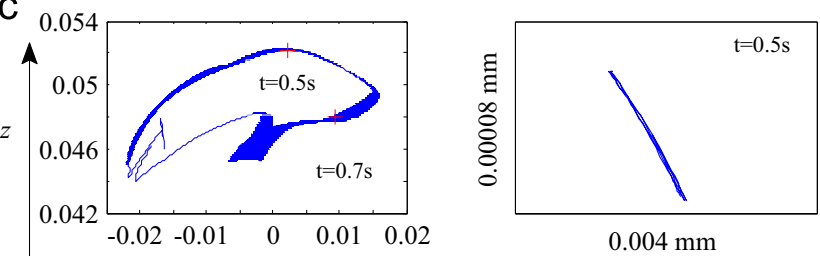

$0.004 \mathrm{~mm}$

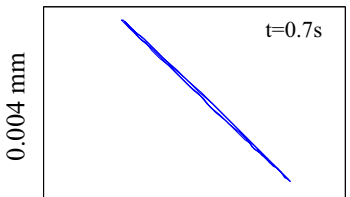

$0.004 \mathrm{~mm}$

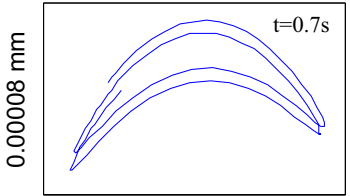

$0.004 \mathrm{~mm}$

Fig. 13. Contact point track and the vibration of the femoral head in $x, y$ and $z$ directions [105]. 
point between the head and cup by altering its macro and micro trajectory. It was also observed that friction-induced vibration can significantly affect the contact pressure and joint moments. It was shown that a low friction coefficient, low loads and high system damping decreased the incidence of hip squeaking [115]. Table 3 summarizes the main potential factors related to hip squeaking in available published literature.

\subsection{High wear rates of noisy hips observed in vivo}

Wear can influence the performance and life expectancy of an implant and has been found to be a key factor in primary failure of artificial hip joints [116,117]. The consequence of wear is often revision surgery to replace the THA with a new one. This is obviously an undesired outcome because of the hardship it imposes on the patient and health budget. Experimental hip simulator and computational studies on CoC and MoM bearings have consistently shown very low wear rates under standard hip simulator conditions which correlates to well-positioned prostheses $[23,68,118-125]$. However, this has not been confirmed by long-term retrieval analyses [21,126-130]. The standard conditions are defined with the femoral head sitting concentrically with the acetabular cup and the acetabular cup with a clinically equivalent inclination angle of less than $55^{\circ}$. Under these ideal conditions very low wear rates have been obtained. In sharp contrast, $\mathrm{CoC}$ and MoM retrievals with elevated wear rates have been associated with steep cup-inclination angle resulting in edge-loading [131-139]. Increased cup inclination angle have been associated with a stripe wear area on the femoral head and an elevated wear rate of alumina CoC retrievals [140]. However, these steep cup-inclination angles exhibited in vitro studies do not lead to high wear levels when tested in-vivo and even the corresponding wear mechanisms [133,135,136,140,141].

Introduction of micro-separation to the gait cycle has however demonstrated edge loading, wear rates and wear mechanisms similar to worn retrievals $[123,132,133,139,142-144]$. Moreover, the loading and motion inputs affect hip implant wear. Fialho et al. [145] showed that the wear rates occurring during a simulated jogging cycle had a twofold increase compared to those of the walking cycle, due to a significant increase in loading. Considering the effect of different motion inputs on wear prediction of hip prostheses indicated that evaluated volumetric wear under the ProSim simulator and the ISO motion and loading conditions are less than that predicted for in-vivo walking motion [146]. In addition, one study obtained that using a 3D sliding distance increased volumetric wear by $18 \%$ compared to a simplified two dimensional flexion-extension analysis [145].

Friction also affects sliding distance and contact stress in artificial hip joints $[23,24,105]$. It has been reported that the femoral head vibrates inside the cup with micron amplitude within the corresponding collision plane and with nanometre amplitude normal to the collision plane due to friction-induced vibration $[19,105]$. This can result in a change in the contact point trajectory and contact stress on both a micro and macro-scale, which can a

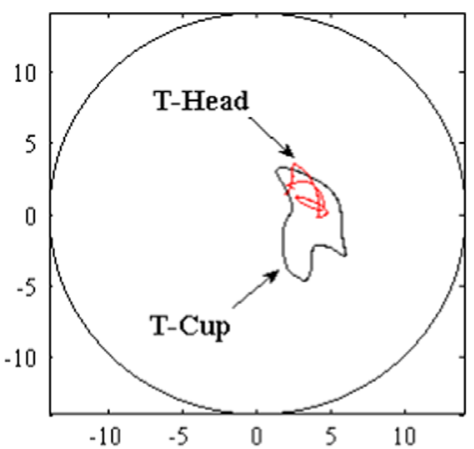

b

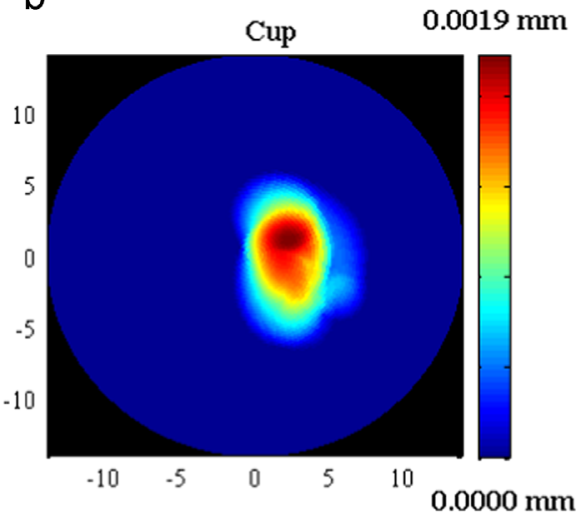

C

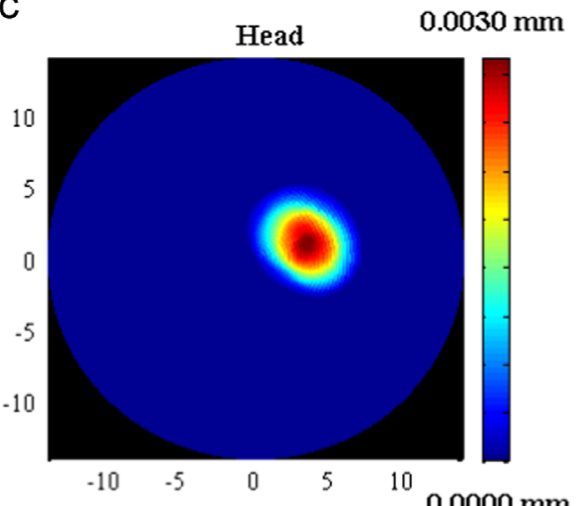

d Posterior

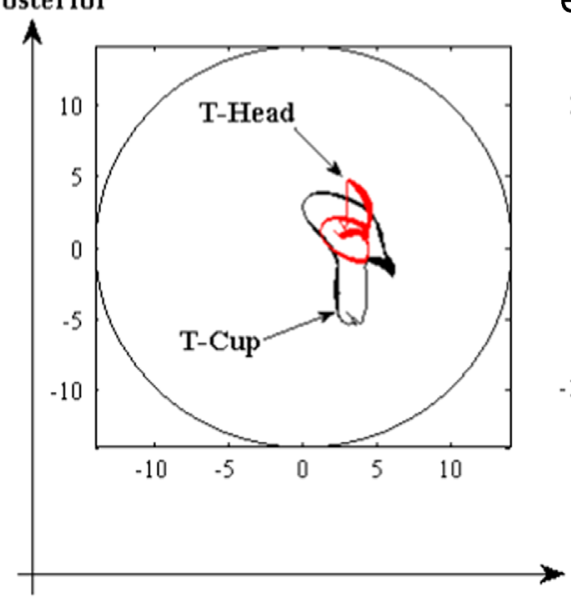

e

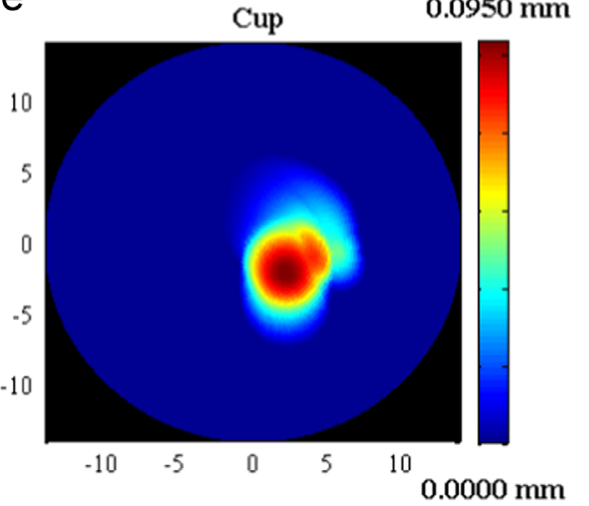

\section{f}

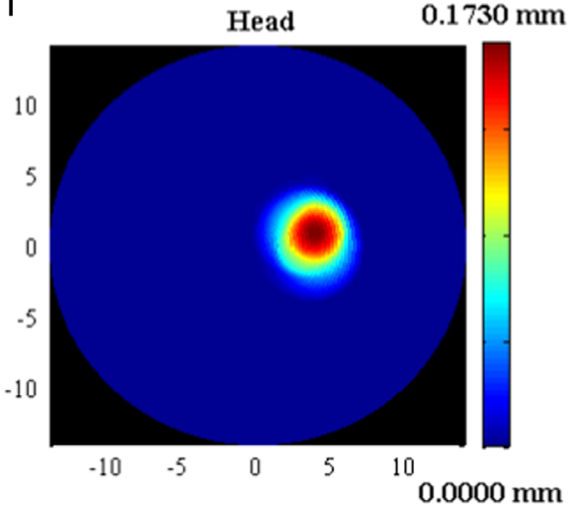

Medial

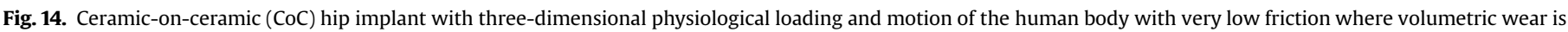

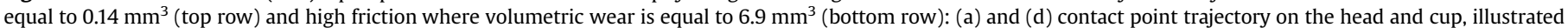
as T-Head and T-Cup, respectively; (b) and (e) linear wear depth on the cup; (c) and (f) linear wear depth on the head [20]. 
affect the final wear profile, Fig. 14. Recently, computational simulations showed that friction-induced vibration can considerably increase wear rates in hard-on-hard hip implants. The occurrence of friction-induced vibration in artificial hip joints can therefore be a cause for high wear rates observed in vivo, Fig. 14. High wear rates and cyclic motions of the contact point between the cup and femoral head due to both daily locomotion and friction-induced vibration can also lead to fracture in the ceramic liner of total hip arthoplasty. Recently, a case study reported the occurrence of ceramic liner fracture for two patients with hip pain and squeaking [147].

As discussed previously, the main potential cause for hip squeaking is friction-induced vibration. Moreover, this phenomenon can lead to significant increases in wear rates of hip implants. It can be concluded that noisy hips may experience higher wear rates compared to silent hips. In this regard, a retrieval study, [21], reported that noisy $\mathrm{CoC}$ hips had a 45 -fold increase in their wear compared to silent hips. Moreover, Askari et al. [20,86,105,148] performed a series of computational studies on hip squeaking and wear prediction of noisy hips showing that noisy hips experience higher wear rates compared to silent hips due to friction-induced vibration, corroborating retrieval studies consistently. Hence, it may be suggested that excessive wear rates are associated with hip squeaking.

\section{Computational models}

In-vivo and retrieval studies have provided data and information on frequencies at which THA squeaking occurs and contributing factors, such as patient, design/material, implant position/orientation [17,43,44,46,64,88]. In addition, experimental and computational studies have been conducted to understand the mechanism of hip squeaking and figure out how modifying the system can remove squeaking $[19,61,105,110,112]$. For a comparison purpose of fundamental frequencies of squeaking hips, Table 4 lists two first unstable frequencies with the corresponding method.

Notwithstanding the benefit of analysing in-vivo mechanics using a non-invasive technique and experimental investigations, computational studies have also proved adept at quantifying parametric features. Thus, computational studies play an important role in understanding THA. The finite element analysis as a popular approach for hip implant design and analysis, and multibody methodology to describe bodies by kinematic relations due

Table 4

Fundamental squeaking frequencies of ceramic hip bearings.

\begin{tabular}{|c|c|c|c|}
\hline & $\begin{array}{l}\text { First frequency } \\
{[\mathrm{Hz}]}\end{array}$ & $\begin{array}{l}\text { Second frequency } \\
{[\mathrm{Hz}]}\end{array}$ & Method \\
\hline Weiss et al. [48] & 5 & 35 & Numerical study \\
\hline Fan et al. [112] & 2700 & 3200 & Numerical study \\
\hline Fan et al. [113] & $1843-2050$ & 3300 & Numerical study \\
\hline $\begin{array}{l}\text { Ouenzerfi et al. } \\
\text { [65] }\end{array}$ & 1759 & & Numerical study \\
\hline $\begin{array}{l}\text { Askari et al. } \\
\text { [86,150] }\end{array}$ & 1700 & $3400-3800$ & Numerical study \\
\hline Askari et al. [105] & $2600-3000$ & $5000-5500$ & Numerical study \\
\hline Walter et al. [43] & 1546 & 3046 & Clinical study \\
\hline Sariali et al. [85] & $2240-2460$ & & Clinical study \\
\hline Currier et al. [110] & $1540-2530$ & $3090-5070$ & Clinical study \\
\hline Weiss et al. [19] & 3400 & 10000 & Experimental study \\
\hline Sariali et al. [85] & 2600 & 5300 & Experimental study \\
\hline Currier et al. [110] & $2400-3617$ & $4800-7235$ & Experimental study \\
\hline $\begin{array}{l}\text { Ouenzerfi et al. } \\
{[65]}\end{array}$ & $2775-3308$ & & Experimental study \\
\hline Weiss et al. [49] & 3350 & & Experimental study \\
\hline
\end{tabular}

to vibrational and dynamical nature of hip squeaking are two main methodologies used to simulate noise emission of ceramic hip implants. These methods are briefly described in the following sections.

\subsection{Finite element method}

The stability of the hip motion equations reflects the likelihood of squeaking of ceramic hip prostheses. Two common techniques for evaluating the stability of a system are (i) transient dynamic analysis; and (ii) complex eigenvalue analysis. A divergent transient solution indicates that the system is unstable. However, this methodology is computationally costly and provides no insight into how the system might be modified to remove the instability On the contrary, the complex eigenvalue method obtains the system eigenvalues and eigenvectors such that it can be revealed which of a system's vibration modes are unstable. This knowledge enables engineers and designers to deal with the unstable system by means of several control methods. Modal frequencies could be moved by either changing components or adding damping to convert the corresponding unstable modes to stable ones. This method can obtain all unstable frequencies in one run for one set of operating conditions, which would be very difficult to achieve with physical experiments. The complex eigenvalue approach was utilized by Weiss et al. [48] to simulate hip squeaking and they proved that this method was feasible. The method was utilized by other researchers to analyse squeaking noise emitted from ceramic hip arthroplasties during previous years $[65,112,113]$. Here, the methodology of the complex eigenvalue analysis is introduced briefly. The equation of motion for a vibrating system can be written as follows

$\mathbf{M u}+\mathbf{C u}+\mathbf{K u}=\mathbf{0}$

where $\mathbf{M}, \mathbf{C}$ and $\mathbf{K}$ are mass, damping and stiffness matrices, respectively, and $\mathbf{u}$ is the displacement vector. Due to friction within the contact area, using the Coulomb friction law, the stiffness matrix has specific properties:

$\mathbf{K}=\mathbf{K}_{s}+\mu \mathbf{K}_{f}$

$\mathbf{K}_{s}$ is the structural stiffness matrix and $\mathbf{K}_{f}$ is the asymmetrical friction induced stiffness matrix and $\mu$ is the friction coefficient. If the friction coefficient decreases with velocity owing to velocitydependent friction coefficient, this effect will be added to Eq. (7) by both modified damping and stiffness matrices. The complementary solution to the homogenous, second order, matrix differential equation, Eq. (7), is in the form given below

$\mathbf{u}=\boldsymbol{\phi} e^{s t}$

Substituting this solution into Eq. (7) yields the complex eigenvalue problem, as follows:

$$
s^{2} \mathbf{M}+s \mathbf{C}+\mathbf{K} \boldsymbol{\phi}=\mathbf{0}
$$

To solve the complex eigenproblem, both the damping matrix and the asymmetric contribution of $\mathbf{K}$ is ignored, which yields to

$$
\left(\omega^{2} \mathbf{M}+\mathbf{K}_{s}\right) \boldsymbol{\phi}=\mathbf{0}
$$

where $\omega$ is an eigenfrequency of the system. Eq. (11) is solved to find the projection subspace formed as $N$ obtained eigenvectors in a matrix, $\left[\boldsymbol{\phi}_{1}, \ldots, \boldsymbol{\phi}_{N}\right]$. Now, the equation of motion is projected onto this subspace as follows:

$$
\begin{aligned}
\mathbf{M}^{*} & =\left[\boldsymbol{\phi}_{1}, \ldots, \boldsymbol{\phi}_{N}\right]^{T} \mathbf{M}\left[\boldsymbol{\phi}_{1}, \ldots, \boldsymbol{\phi}_{N}\right] \\
\mathbf{C}^{*} & =\left[\boldsymbol{\phi}_{1}, \ldots, \boldsymbol{\phi}_{N}\right]^{T} \mathbf{C}\left[\phi_{1}, \ldots, \boldsymbol{\phi}_{N}\right] \\
\mathbf{K}^{*} & =\left[\boldsymbol{\phi}_{1}, \ldots, \boldsymbol{\phi}_{N}\right]^{T} \mathbf{K}\left[\phi_{1}, \ldots, \boldsymbol{\phi}_{N}\right]
\end{aligned}
$$




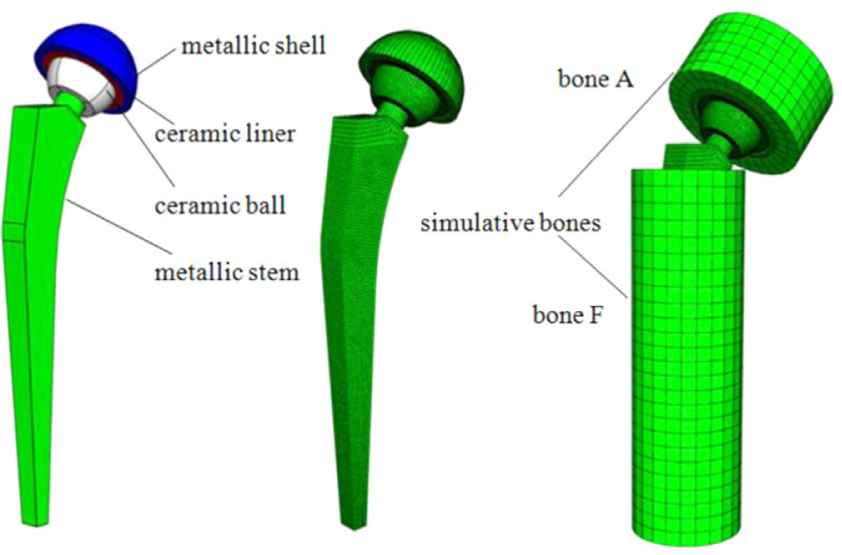

Fig. 15. FE model of a hip endoprosthesis system [112].

Then, the complex eigenproblem is simplified to

$\left(s^{2} \mathbf{M}^{*}+s \mathbf{C}^{*}+\mathbf{K}^{*}\right) \boldsymbol{\phi}^{*}=0$

The characteristic equation, Eq. (13), has non-trivial solutions if the matrix in parenthesis is singular. It happens only for complex eigenvalues, $s\left(s_{i}\right)$. The corresponding vectors $\boldsymbol{\phi}_{i}^{*}$ are the eigenvectors of the projected system. Finally, the complex eigenvectors of the original system can be acquired by

$\boldsymbol{\phi}=\left[\boldsymbol{\phi}_{1}, \ldots, \boldsymbol{\phi}_{N}\right]^{T} \boldsymbol{\phi}^{*}$

Both the obtained eigenvalues and eigenvectors may or may not be complex. Assuming an eigenvalue to be $s_{i}=\alpha_{i}+i \omega_{i}$, where $\alpha$ is the real part and $\omega$ is the imaginary part of $s$ for the $i$ th mode, the motion for each mode is written as

$\mathbf{u}_{i}=\boldsymbol{\phi}_{i} e^{\left(\alpha_{i}+j \omega_{i}\right) t}+\boldsymbol{\phi}_{i} e^{\left(\alpha_{i}-j \omega_{i}\right) t}$

when the real part of the ith eigenvalue, $\alpha_{i}$, is positive, the system becomes unstable and squeaking noise emits.

In order to simulate squeaking using commercial FE software, ABAQUS version 6.4 and above provide a complex eigenvalue solution [112]. Moreover, a recent study used the commercial FE software ANSYS Workbench to incorporate the complex eigenvalue method to study hip squeaking [65]. This new capability uses direct contact coupling at the friction sliding interface described by Yuan [155] and there is no need to introduce contact springs at the interface and $\mathbf{K}_{f}$. The fundamental procedures for applying ABAQUS to perform the complex eigenvalue analysis of ceramic hip prostheses are as follows: (i) Nonlinear static analysis of the ceramic hip endoprosthesis system for applying joint resultant force; (ii) nonlinear static analysis to impose the rotational speed on the femoral components; (iii) normal mode analysis to extract natural frequency without friction coupling; and (iv) complex eigenvalue analysis that incorporates the effect of friction coupling.

Fig. 15 illustrates a CoC THA with a metallic shell, ceramic liner and ball, metallic stem and a simulative bone beside acetabular components, denoted as bone $A$, and a simulative bone beside femoral components, denoted as bone $F$. Material properties of hip components are listed in Table 5. In previous studies, all materials were assumed homogeneous, isotropic and linear elastic and the element to mesh the model was the 8-noded hexahedral element. The femoral bone and acetabular bone are simulated as cylinders due to the simplification of computational analyses. The hip joint resultant force was set as either $100 \mathrm{~N}$ or $1500 \mathrm{~N}$ applied at the end of the stem as depicted in Fig. 16 [48,112,113]. A relative rotational motion between the head and the liner was imposed as $1 \mathrm{rad} / \mathrm{s}$ around the $Y$-axis to produce friction. Weiss et al. [48] explained that the applied spinning motion is easily extendable to
Table 5

The parameters of prosthetic materials [112]

\begin{tabular}{llll}
\hline Materials & Density $\left[\mathrm{kg} / \mathrm{m}^{3}\right]$ & Young's modulus $\left[\mathrm{N} / \mathrm{m}^{2}\right]$ & Poisson ratio \\
\hline Ti6Al4V & 4500 & $1.10 \times 10^{11}$ & 0.3 \\
Ceramic & 4370 & $3.58 \times 10^{11}$ & 0.23 \\
Simulative bone & 1932 & $2.0 \times 10^{10}$ & 0.3 \\
\hline
\end{tabular}

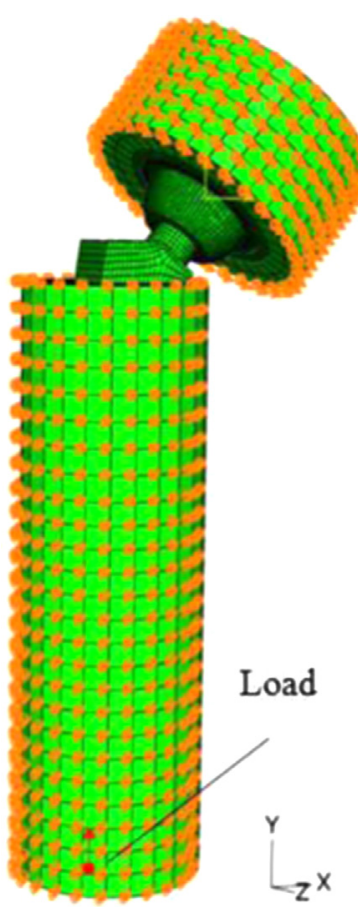

Fig. 16. Loading and boundary condition [112].

the general kinematic motion observed in hip implants in vivo that in fact consists of a superposition of spin and translation. However, there is no study yet to model a hip implant subject to the general kinetic motion, using the finite element method. The bone $A$ is completely fixed and the edge of the bone $F$ is supposed to be fixed to assure the original placement of the system. A Coulomb-type friction force with a fixed constant coefficient of friction during each numerical experiment was utilized to allow for a proper identification of unstable parameter-configurations. It should be noted that no FE study to date has taken measured friction-velocity curves into account. Moreover, the effect of slip-stick friction and joint clearance on hip squeaking has not been described using this methodology.

\subsection{Multibody methodology}

The human body has relatively rigid bones, connected by special joints capable of large anatomical articulations. From a mechanical point-of-view, this description of the human body is similar to that of a multibody mechanical system. However, the human body system is far more complex than the great majority of the multibody systems. Its components have a complex behaviour due to deformations associated with the soft tissues such as the muscles, tendons and ligaments, and due to the complexity of the anatomical articulations relative to the standard mechanical joints [156]. Multibody-based methodologies have been developed in such a way that, besides the representation of mechanical systems made only of rigid components [157], they can also represent deformable bodies [158]. In a broad sense, much of the research 


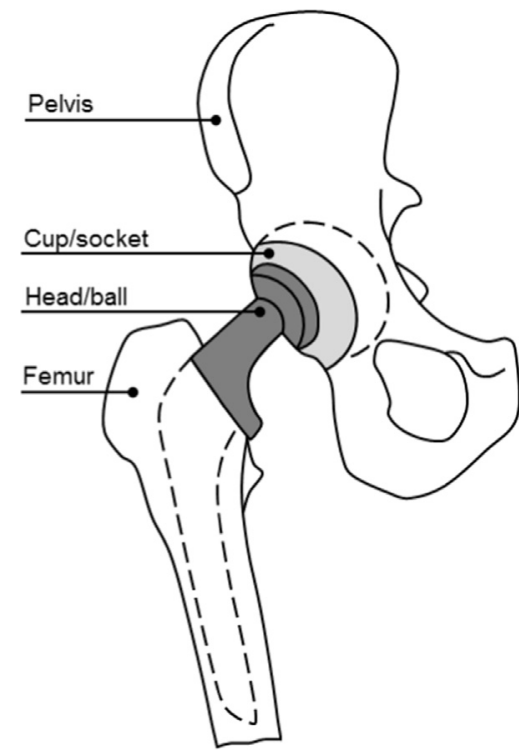

Fig. 17. Schematic representation of the artificial hip replacement.

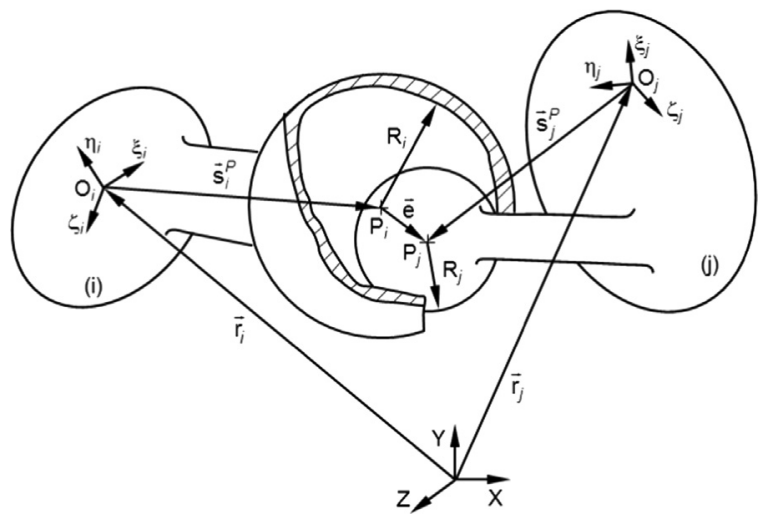

Fig. 18. General configuration of an artificial hip joint in a multibody system [162].

developed with the purpose to simulate daily human tasks is based on the assumption that the joints that constrain the system's components are considered as ideal or perfect joints, such as spherical, revolute and universal joints. Nevertheless, with this approach a decrease in the kinematic and dynamic precision can occur when compared with the living body because the idealized models fail to capture more complex aspects of joint kinematics and dynamics [159].

In the field of multibody system dynamics, computational methods which represent complex phenomena such as contact geometry, friction phenomena, wear and lubrication have been developed [160]. However, the application of these methods in the field of biomechanical system dynamics has been limited. A possible reason is that much of the biomechanical simulation is based upon inverse dynamics, where movement of all degrees-offreedom is entered into the analysis leading to a presumption of simple joint kinematics. For most applications concerning simple models, this is a reasonable assumption, but for detailed investigations of more complex joints, such as the THA it is not, Fig. 17. In contrast, Askari and his co-authors [150] considered a planar dynamic model of the THA, in which the head and cup are modelled as contacting components [161]. They reported that potential reason for hip squeaking was friction-induced vibration due to stick-slip friction and negative friction-velocity slope. The model developed [148] was extended to a spatial multibody dynamic hip model, taking into account the physiological three-dimensional rotation motions and forces for studying nonlinear dynamics and vibration of THA as well as addressing hip squeaking. Kang $[87,114]$ developed a theoretical dynamic model for the ball joint as a sphere attached to a rotating beam and in contact with a semi-spherical rigid socket. A recent study also investigated friction-induced vibration in THAs by considering contact between the cup and the femoral head [115]. In what follows, the methodology of the multibody methodology is introduced briefly.

It is well known that the equations of motion for a multibody dynamic system with holonomic constraints can be written as [19],

$\mathbf{M} \ddot{\mathbf{q}}=\mathbf{g}+\mathbf{g}^{(c)}$

$\Phi(\mathbf{q}, t)=0$

in which $\mathbf{M}$ is the system mass matrix, $\mathbf{q}$ generalized coordinates of the system, $\ddot{\mathbf{q}}$ the acceleration vector, and $\mathbf{g}$ the generalized force vector containing all external forces and moments. The bodies in the multibody system are interconnected by joints imposing constraints on the bodies' relative motion. Expressing these conditions as algebraic equations in terms of a generalized coordinate and time, $t$, holonomic kinematic constraints defined in Eq. (17) are introduced. Moreover, $\mathbf{g}^{(c)}$ is the vector of constraint reaction equations, which can be rewritten by means of the Jacobian matrix of the constraint equations $\left(\boldsymbol{\Phi}_{\mathbf{q}}\right)$ and the vector of Lagrange multipliers $(\boldsymbol{\lambda})$ as [19]

$\mathbf{g}^{(c)}=-\Phi_{q}^{T} \lambda$

substituting Eq. (18) in Eq. (16) yields,

$\mathbf{M} \ddot{\mathbf{q}}+\Phi_{\mathbf{q}}^{T} \lambda=\mathbf{g}$

Furthermore, differentiating Eq. (17) twice with respect to time, the constraint equation can be written as follows:

$\boldsymbol{\Phi}_{\mathbf{q}} \ddot{\mathbf{q}}=-\left(\boldsymbol{\Phi}_{\mathbf{q}} \dot{\mathbf{q}}\right)_{\mathbf{q}} \dot{\mathbf{q}}-2 \boldsymbol{\Phi}_{\mathbf{q} t} \dot{\mathbf{q}}-\boldsymbol{\Phi}_{t t}=\boldsymbol{\gamma}$

where $\boldsymbol{\gamma}$ is a vector function of velocity and position of the system as well as time. As a consequence, both Eqs. (19) and (20) yield a system of differential algebraic equations to be solved for $\ddot{\mathbf{q}}$ and $\boldsymbol{\lambda}$, given by

$\left[\begin{array}{cc}\mathbf{M} & \boldsymbol{\Phi}_{\mathbf{q}}^{T} \\ \boldsymbol{\Phi}_{\mathbf{q}} & 0\end{array}\right]\left\{\begin{array}{l}\ddot{\mathbf{q}} \\ \lambda\end{array}\right\}=\left\{\begin{array}{l}\mathbf{g} \\ \boldsymbol{\gamma}\end{array}\right\}$

Eq. (21) can be solved only if the coefficient matrix of Eq. (21) is non-singular. This can be achieved by having a positive definite mass matrix and the Jacobian matrix $\boldsymbol{\Phi}_{\mathbf{q}}$ full row rank [5]. A general configuration of a hip implant modelled as a multibody system is shown in Fig. 18, and the equations of motion described above addresses its kinetic and kinematic.

Normal contact force and tangential friction force in the articulation surface between the femoral head and cup play important roles in multibody dynamics formulations. There are different approaches to deal with contact-impact events which could be categorised into two main groups, non-smooth dynamics formulation and continuous analysis [163]. In the first group, colliding bodies are assumed to be rigid and unilateral constraints are used to deal with the contact mechanics. On the other hand the continuous methods, also known as either compliant or penalty methods, are considered deformable approaches since the contacting bodies are allowed to deform at the contact zone. Moreover, the corresponding contact forces are evaluated as a function of indentation and compliance of articulating surfaces [163]. As an example, a modified Hertz contact law proposed by Lankarani and Nikravesh [164], which belong to the second group, 


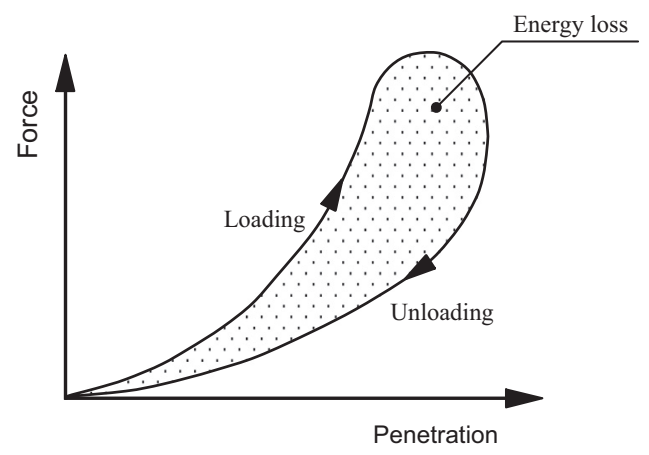

Fig. 19. Force versus penetration [164].

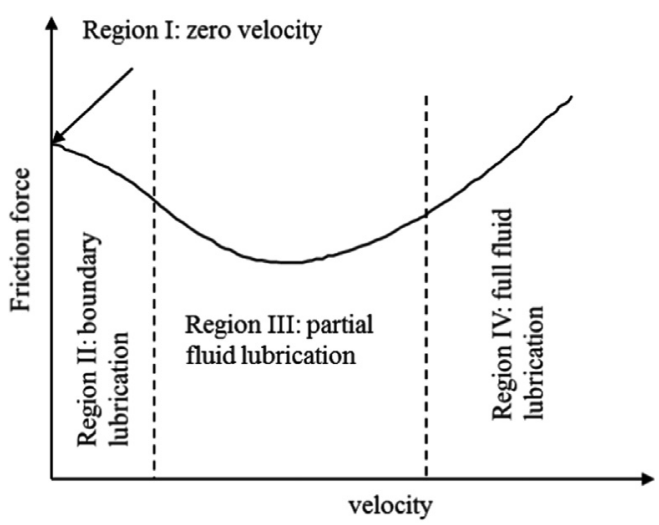

Fig. 20. Stribeck friction-velocity curve showing four regimes [172].

is given by

$\mathbf{F}^{n}=-K \delta^{\frac{3}{2}}\left(1+\frac{3\left(1-c_{e}^{2}\right)}{4} \frac{\dot{\delta}}{\dot{\delta}^{(-)}}\right) \mathbf{n}$

where $\dot{\delta}$ and $\dot{\delta}^{(-)}$are the relative penetration velocity and the initial contact velocity, respectively, and $c_{e}$ is the coefficient of restitution. The generalized stiffness parameter $K$ depends on the geometry and physical properties of the contacting surfaces [10]. This contact model also takes energy loss due to impact and Fig. 19 shows how energy loss during loading and unloading of impact process is captured.

To compute the tangential friction forces, one of the first and simplest friction laws is Coulomb friction law. Coulomb (17361806) determined that the frictional force between two bodies which are pressed together with a normal force can be calculated by the product of normal force and friction coefficient. Although the friction coefficient suggested by Coulomb is assumed to be constant with increasing the sliding speed, experimental tests have demonstrated that friction coefficient is a function of the relative velocity, Panovko and Gubanova [165] and Ibrahim [166]. Different friction-speed models have therefore been proposed to take the velocity dependence of friction into account. Moreover, hip implant contact is lubricated and the friction force depends on the friction-speed regimes: (i) boundary lubrication (no dependence on the velocity); (ii) mixed fluid lubrication; and (iii) full fluid-film lubrication, as described in the Section 2.4 and shown in Fig. 12.

Generally, the friction decreases with increased relative velocity until a mixed or full film lubrication is obtained, after which the friction can be constant, increase, or decrease with increasing the sliding speed due to viscous and thermal effects. Stribeck [167-169] suggested a model known as the Stribeck model which can convey the friction behaviour in the different four friction regions. The model can be written as follows:

$F=\left(F_{c}+\left(F_{s}-F_{c}\right) e^{-\left(|v| / v_{s}\right)^{i}}\right) \operatorname{sign}(v)+k_{v} v$

where $F$ is the friction force, $v$ the sliding velocity, $F_{c}$ the Coulomb sliding friction force, $F_{s}$ the maximum static friction force, $v_{s}$ the sliding speed coefficient, $k_{v}$ the viscous friction coefficient, and $i$ an exponent. This model is represented in Fig. 20. The reason of decreasing friction with increasing velocity in dry sliding metallic bodies was experimentally investigated, and was due to the material softening as a result of high temperatures generated at the contact surfaces $[170,171]$. The Stribeck model can provide a good representation of the friction between sliding surfaces and it can describe the stick-slip phenomenon and the negative damping effect.

\subsubsection{Operating conditions}

Like the natural joint, THA in-vivo must be able to work under transient and wide range 3D physiological operating conditions, therefore triaxial load and angular velocity should be considered. The most complete database for loading conditions has been provided by Bergman et al., who measured hip forces in nine daily activities, e.g. walking and running, among others. An example of a normal walking gait cycle is depicted in Fig. 21, showing the three components of the hip force and the corresponding hip angles. For simplification purpose, the main (vertical) load component and flexion-extension motion of the walking cycle are usually considered, according to the ISO standard 14242-1, depicted in Fig. 22. The operating conditions are applied to the model as follow: (i) the cup is assumed to be stationary and the forces are applied to the centre of the femoral head; and (ii) the 3D physiological motions are applied to the femoral head.

\section{Future research directions}

The main limitation of previous computational studies using either finite element method or multibody simulation method is that they have not taken the effect of fluid-film lubrication on the system outcome into account. It can be physically deduced that friction coefficient alters over the gait cycle due to the alteration of fluid film thickness [175]. Moreover, fluid-film lubrication can improve the articulation of the head and cup so it can significantly affect hip squeaking [61]. Therefore, the main future direction should address lubrication effects into numerical formulations to assess hip squeaking.

Using multibody dynamics method, rotational motions and forces of the femoral head are in-vivo inputs so where relevant data is available developed models are applicable. However, there is lack of corresponding information when artificial hip joint is experiencing adverse conditions such as edge-loading and impingement. Hence future work should include whole leg motion with muscles and other soft tissues taken into consideration and then solving equations using inverse dynamics methods to obtain related motions and forces in the case of edge-loading, impingement and microseparation. Only then can the effect of these adverse conditions on hip squeaking over the gait cycle be investigated.

In addition to these adverse conditions, available multibody models do not simulate elasticity of the contacting bodies, and therefore cannot predict the effect of contact forces and impact on the acetabular components (i.e. distortion of the ceramic insert in the titanium shell) as a potential cause of hip squeaking. Therefore, future work can include the elasticity of contacting surfaces. Moreover, previous studies have only considered normal walking activity while hip squeaking occurs due to other daily activities as 

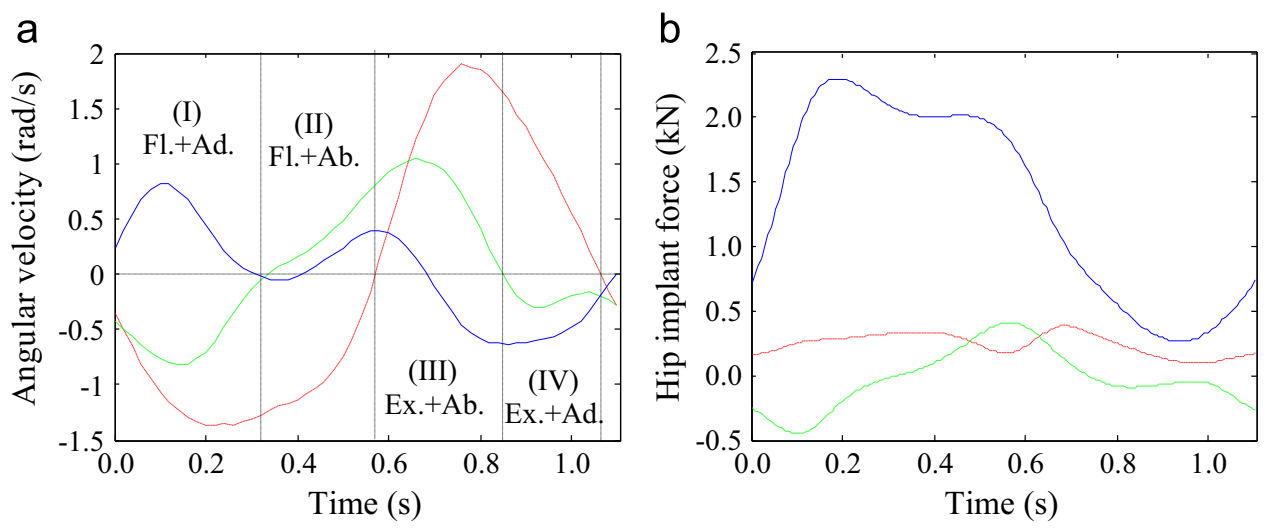

Fig. 21. (a) Angular velocities where $\omega_{z}(\mathrm{IER}) ; \omega_{y}(\mathrm{AA}) ; \omega_{x}(\mathrm{FE})$; (b) physiological adopted forces with $f_{z}$ (vertical); $f_{y}(\mathrm{~A}-\mathrm{P}) ; f_{x}(\mathrm{M}-\mathrm{L})$ for the gait cycle [173].
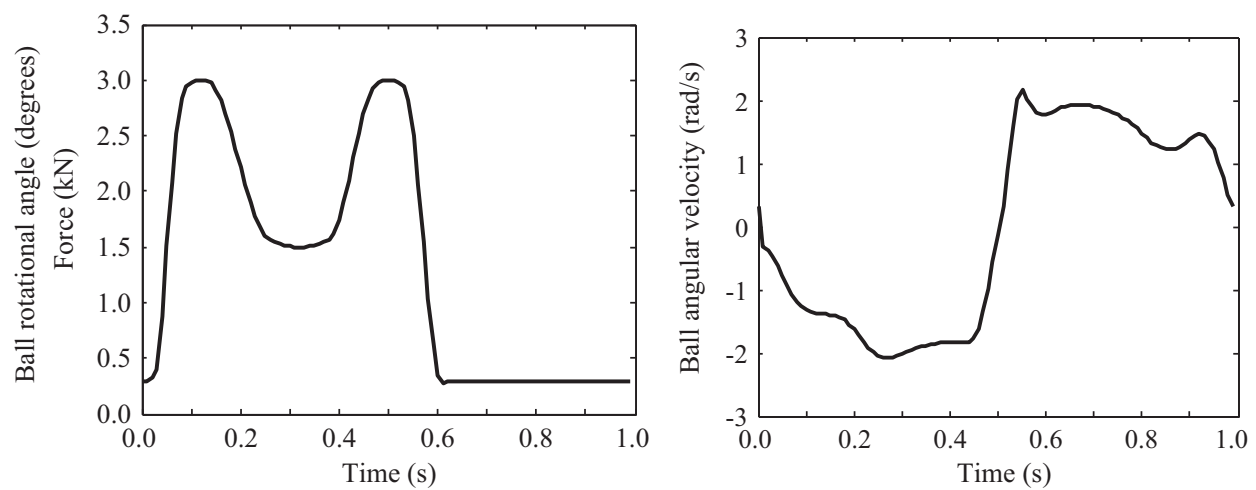

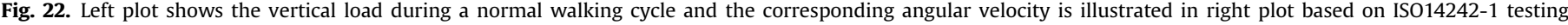
standard [174].

well. So the future works could study different daily activities and provide data on hip squeaking due to different daily activities.

Friction was found as the main cause of hip squeaking in ceramic-on-ceramic hip implants. Most of previous studies on simulating hip implant motions employed the Coulomb friction force model which does not account for the Stribeck effect, stickslip friction and the extremely small displacement of surface asperities. A few investigations have employed a modified friction model including the Stribeck phenomenon to study the dynamics of artificial hip joints, but these models did not account for nonlinear pre-slip displacements of the friction interface $[87,105,115]$. So when relative velocity approaches zero, the friction force is calculated to be zero. In a real sliding scenario, tangential friction force is not zero when very small displacements of surface asperities occur in the contact area. It can significantly affect the kinetic of articulating hip surfaces. An object for future research is to develop a modified friction force model to include stick-slip, Stribeck effect and pre-slip displacement at microscopic level to model nonlinear dynamics and vibration of artificial hip joints, considering hip squeaking.

Although it has been clinically and computationally illustrated that hip squeaking may be associated with higher wear rates compared to silent hips, these results should be validated against controlled physical experiments and gain a better understanding of the mechanism behind articulation and evolution of hip squeaking and wear. Moreover, a recent case report showed ceramic liner fracture for two patients with hip pain and squeaking. There may be an association between squeaking and liner fracture in ceramic hip prostheses and it can be deduced based on an engineering point of view as well. However, this relation has not been proved yet and needs more investigation clinically, experimentally and computationally. Generally, one of main research direction in this field is to discover if hip squeaking has consequences which threaten the life quality and wellbeing of patients and in turn make appropriate clinical and engineering decisions to prevent adverse consequences.

A recent study, which investigated hip squeaking using the complex eigenvalue method, took into account the influence of the soft tissue around the bone on hip squeaking [65]. They illustrated a significant decrease in fundamental squeaking frequencies that are comparable with in-vivo frequencies. It was then discussed that the discrepancy between in-vivo and in-vitro frequencies can be justified by the mass added to the dynamic system due to the presence of the soft tissues. Further experimental and computational studies are required to reveal the effect of both the soft tissues and the bone existing around THA on squeaking. In addition, there are no studies yet to address their damping effects on the vibrational characteristics of the system.

It is now known that the main reason of hip squeaking is friction-induced vibration. As Askari et al. and Fan et al. demonstrated, associated unstable frequencies and vibration modes can be determined using numerical methods [105,112]. From an engineering point of view, ceramic hip implants might be modified by either changing component geometry and/or materials, or by adding damping to convert the unstable modes to stable ones. A recent advance is the development of two new ceramics for THA bearings, namely alumina-toughened zirconia (ATZ) and zirconiatoughened alumina (ZTA). They have shown a 5-fold reduction in the overall wear rate compared to the older alumina ceramics $[123,176,177]$. Moreover, studies have suggested either addition of damping materials to acetabular components or increase in stiffness of the femoral stem can improve the stability of THA $[112,113]$. More investigations are required to find feasible and 
reliable solutions for modifying the mechanical system of total hip arthroplasty to remove squeaking.

\section{Concluding remarks}

As has been discussed, hip squeaking does not occur in the presence of fluid film lubrication due to non-contact between articulating surfaces. However, the fluid film is disrupted by increased surface roughness, particulate metal debris between articulating surfaces, an alteration in the property of synovial fluid and/or abnormal behaviours in prosthetic hip joints such as edge loading and micro-separation. The fluid-film lubrication regime is converted to either the mixed lubrication or boundary lubrication. Consequently, friction coefficient generally increases which can lead to hip squeaking. Micro-separation, rim-neck impingement and edge-loading are abnormal motion behaviours in THA which prevent the bearing from producing optimum fluid-film lubrication. In these cases, there are poor lubrication conditions and extreme contact stresses due to the low conformity of the bearing surfaces.

In the absence of fluid-film lubrication, bearing surfaces slide against each other and friction develops, acting as a resistance to relative motion. Friction can induce vibration in hip articulation owing to instability in the structural system such as negativesloping friction, stick-slip, contact force changes, mode-coupling, and material nonlinearity. Moreover, friction-induced vibration can significantly increase wear rates in THA. Hip squeaking may therefore be associated with high wear rates of noisy hips compared to silent hips. High wear rates may lead to the occurrence of ceramic liner fracture, but it needs more investigations to assess as a potential consequence of hip squeaking. There is no more information on hip squeaking consequences.

\section{Acknowledgements}

The first author gratefully acknowledges Macquarie University for International Macquarie University Research Excellence Scholarship (iMQRES)-No. 2010017. The second author would like to thank to the Portuguese Foundation for Science and Technology through the project UID/EEA/04436/2013.

\section{References}

[1] Laupacis A, Bourne R, Rorabeck C, Feeny D, Wong C, Tugwell P, Leslie K, Bullas R. The effect of elective total hip replacement on health-related quality of life. J Bone Jt Surg Am 1993;75:1619-26.

[2] Mattei L, Di Puccio F, Piccigallo B, Ciulli E. Lubrication and wear modelling of artificial hip joints: a review. Tribol Int 2011;44(5):532-49.

[3] Callaghan JJ, Rosenberg AG, Rubash HE. The adult hip. Philadelphia, USA Lippincott Williams and Wilkins; 2007.

[4] Dearnaley G, Arps JH. Biomedical applications of diamond-like carbon (DLC) coatings: a review. Surf Coat Technol 2005;200(7):2518-24.

[5] Kurtz S, Ong K, Lau E, Mowat F, Halpern M. Projections of primary and revision hip and knee arthroplasty in the United States from 2005 to 2030. Bone Jt Surg 2007;89(4):780-5.

[6] Berry DJ, Harmsen WS, Cabanela ME, Morrey BF. Twenty-five-year survivorship of two thousand consecutive primary charnley total hip replacements. J Bone Jt Surg Am 2002;84-A(2).

[7] Caton J, Prudhon JL. Over 25 years survival after Charnley's total hip arthroplasty. Int. Orthop. 2011;35(2):185-8.

[8] Australian Orthopaedic Association National Joint Replacement RegistryAnnual report 2013, 2013.

[9] Learmonth ID, Young C, Rorabeck C. The operation of the century: total hip replacement. Lancet 2007;370(9597):1508-19.

[10] Delaunay C, Petit I, Learmonth ID, Oger P, Vendittoli PA. Metal-on-metal bearings total hip arthroplasty: the cobalt and chromium ions release concern. Orthop Traumatol: Surg Res 2010;96(8):894-904.
[11] Boutin P. Arthroplastie totale de la hanche par prothése en alumine frittée. Etude expérimentale et premières applications cliniques. Rev Chir Orthop 1972;58:229-46.

[12] Manley MT, Sutton K. Bearings of the future for total hip arthroplasty. J Arthroplast 2008:23(7):47-50.

[13] Fisher J, Jin Z, Tipper J, Stone M, Ingham E. Tribology of alternative bearings. Clin Orthop Relat Res 2006;453:25-34.

[14] Capello WN, D'Antonio JA, Feinberg JR, Manley MT, Naughton M. Ceramicon-ceramic total hip arthroplasty: update. J Arthroplast 2008;23(7):39-43.

[15] Chang JD, Kamdar R, Yoo JH, Hur M, Lee SS. Third-generation ceramic-onceramic bearing surfaces in revision total hip arthroplasty. J Arthroplast 2009;24(8):1231-5.

[16] Lee YK, Yoo JJ, Koo KH, Yoon KS, Kim HJ. Metal neck and liner impingement in ceramic bearing total hip arthroplasty. J Orthop Res 2011;29(2):218-22.

[17] Restrepo C, Parvizi J, Kurtz SM, Sharkey PF, Hozack WJ, Rothman RH. The noisy ceramic hip: is component malpositioning the cause? J Arthroplast 2008;23(5):643-9.

[18] Parvizi J, Adeli B, Wong JC, Restrepo C, Rothman RH. A squeaky reputation: the problem may be design-dependent. Clin Orthop Relat Res 2011;469 (6): 1598-605.

[19] Weiss C, Hothan A, Huber G, Morlock MM, Hoffmann NP. Friction-induced whirl vibration: root cause of squeaking in total hip arthroplasty. J Biomech 2012;45(2):297-303.

[20] Askari E, Flores P, Dabirrahmani D, Appleyard R. Dynamic modeling and analysis of wear in spatial hard-on-hard couple hip replacements using multibody systems methodologies. Nonlinear Dyn 2015. http://dx.doi.org/ 10.1007/s11071-015-2216-9.

[21] Walter WL, Kurtz SM, Esposito C, Hozack W, Holley KG, Garino JP, Tuke MA. Retrieval analysis of squeaking alumina ceramic-on-ceramic bearings. J Bone Jt Surg 2011:93-B:1597-601.

[22] Askari E, Flores P, Dabirrahmani D, Appleyard R. Wear prediction of ceramicon-ceramic artificial hip joints. In: Flores P, Viadero F, editors. New trends in mechanism and machine science, from fundamentals to industrial applications. Springer; 2015.

[23] Uddin MS, Zhang LC. Predicting the wear of hard-on-hard hip joint prostheses. Wear 2013;301(1-2):192-200.

[24] Mattei L, Di Puccio F. Wear simulation of metal-on-metal hip replacements with frictional contact. J Tribol 2013;135(2):021402.

[25] Liu F, Leslie I, Williams S, Fisher J, Jin Z. Development of computational wear simulation of metal-on-metal hip resurfacing replacements. J. Biomech 2008;41(3):686-94

[26] Amstutz HC, editor. Evolution of hip arthroplasty. New York, NY: Churchill Livingstone; 1991.

[27] Charnley J. Low friction arthroplasty of the hip: theory and practice. Berlin: Springer-Verlag; 1979.

[28] Jarrett CA, Ranawat A, Bruzzone M, Rodriguez J, Ranawat C. The squeaking hip: a phenomenon of ceramic-on-ceramic total hip arthroplasty. J Arthroplast 2007;22(2):302.

[29] Keurentjes JC, Kuipers RM, Wever DJ, Schreurs BW. High incidence of squeaking in THAs with alumina ceramic-on-ceramic bearings. Clin Orthop Relat Res 2008;466(6):1438-43.

[30] Ki SC, Kim BH, Ryu JH, Yoon DH, Chung YY. Squeaking sound in total hip arthroplasty using ceramic-on-ceramic bearing surfaces. J Orthop Sci $2011 ; 16(1): 21-5$.

[31] Mai K, Verioti C, Ezzet KA, Copp SN, Walker RH, Colwell CW. Incidence of 'squeaking' after ceramic-on-ceramic total hip arthroplasty. Clin Orthop Relat Res 2010;468(2):413-7.

[32] Chen WM, Wu PK, Chen CF, Huang CK, Liu CL, Chen TH. No significant squeaking in total hip arthroplasty: a series of 413 hips in the Asian people. J Arthroplast 2012;27(8):1575-9.

[33] Cogan A, Nizard R, Sedel L. Occurrence of noise in alumina-on-alumina total hip arthroplasty. A survey on 284 consecutive hips. Orthop Traumatol: Surg Res 2011;97(2):206-10.

[34] D'Antonio JA, Capello WN, Naughton M. Ceramic bearings for total hip arthroplasty have high survivorship at 10 years. Clin Orthop Relat Res 2012;470(2):373-81.

[35] Haq RU, Park KS, Seon JK, Yoon TR. Squeaking after third-generation ceramic-on-ceramic total hip arthroplasty. J Arthroplast 2012;27(6):909-15.

[36] Kiyama T, Kinsey TL, Mahoney OM. Can squeaking with ceramic-on-ceramic hip articulations in total hip arthroplasty be avoided? J Arthroplast 2013;28 (6):1015-20.

[37] Kuo FC, Liu HC, Chen WS, Wang JW. Ceramic-on-ceramic total hip arthroplasty: incidence and risk factors of bearing surface-related noises in 125 patients. Orthopedics 2012;35(11):e1581-5.

[38] Owen D, Russell N, Chia A, Thomas M. The natural history of ceramic-onceramic prosthetic hip squeak and its impact on patients. Eur J Orthop Surg Traumatol 2014;24(1):57-61.

[39] Owen DH, Russell NC, Smith PN, Walter WL. An estimation of the incidence of squeaking and revision surgery for squeaking in ceramic-on-ceramic total hip replacement. Bone Jt J 2014:96-B:181-7.

[40] Back DL, Dalziel R, Young D, Shimmin A. Early results of primary Birmingham hip resurfacings. J Bone Jt Surg 2005;87-B:324-9.

[41] Murphy SB, Ecker TM, Tannast M. Incidence of squeaking after alumina ceramic-ceramic total hip arthroplasty. J Arthroplast 2008;23(2):327. 
[42] McDonnell SM, Boyce G, Baré J, Young D, Shimmin AJ. The incidence of noise generation arising from the large-diameter Delta Motion ceramic total hip bearing. BoneJt J 2013;95-B:160-5.

[43] Walter WL, Waters TS, Gillies M, Donohoo S, Kurtz SM, Ranawat AS, Hozack WJ, Tuke MA. Squeaking hips. J Bone Jt Surg 2008;90(4):102-11.

[44] Swanson TV, Peterson DJ, Seethala R, Bliss RL, Spellmon CA. Influence of prosthetic design on squeaking after ceramic-on-ceramic total hip arthroplasty. J Arthroplast 2010;25(6):36-42.

[45] Walter WL, O'Toole GC, Walter WK, Ellis A, Zicat BA. Squeaking in ceramicon-ceramic hips: the importance of acetabular component orientation. J Arthroplast 2007;22(4):496-503.

[46] Sexton SA, Yeung E, Jackson MP, Rajaratnam S, Martell JM, Walter WL, Zicat BA, Walter WK. The role of patient factors and implant position in squeaking of ceramic-on-ceramic total hip replacements. J Bone Jt Surg 2011;93:439-42.

[47] Baek SH, Kim SY. Cementless total hip arthroplasty with alumina bearings in patients younger than fifty with femoral head osteonecrosis. J Bone Jt Surg 2008;90(6):1314-20.

[48] Weiss C, Hothan A, Morlock MM, Hoffmann N. Friction-induced vibration of artificial hip joints. GAMM-Mitteilungen 2009;32(2):193-204.

[49] Weiss C, Gdaniec P, Hoffmann NP, Hothan A, Huber G, Morlock MM. Squeak in hip endoprosthesis systems: an experimental study and a numerical technique to analyze design variants. Med Eng Phys 2010;32(6):604-9.

[50] Bernasek T, Fisher D, Dalury D, Levering M, Dimitris K. Is metal-on-metal squeaking related to acetabular angle of inclination? Clin Orthop Relat Res 2011:469(9):2577-82.

[51] Walter WL, Insley GM, Walter WK, Tuke MA. Edge loading in third generation alumina ceramic-on-ceramic bearings. J Arthroplast 2004;19(4):402-13.

[52] Restrepo C, Post ZD, Kai B, Hozack WJ. The effect of stem design on the prevalence of squeaking following ceramic-on-ceramic bearing total hip arthroplasty. J Bone Jt Surg 2010;92(3):550-7.

[53] Walter WL, Yeung E, Esposito C. A review of squeaking hips. Orthop Adv 2010;18(6):319-26.

[54] Choi IY, Kim YS, Hwang KT, Kim YH. Incidence and factors associated with squeaking in alumina-on-alumina THA. Clin Orthop Relat Res 2010;468 (12):3234-9.

[55] Chevillotte C, Pibarot V, Carret JP, Bejui-Hugues J, Guyen O. Hip squeaking: a 10-year follow-up study. J Arthroplast 2012;27(6):1008-13.

[56] Jarrett CA, Ranawat AS, Bruzzone M, Blum YC, Rodriguez JA, Ranawat CS. The squeaking hip: a phenomenon of ceramic-on-ceramic total hip arthroplasty. J Bone Jt Surg 2009;91(6):1344-9.

[57] Hothan A, Huber G, Weiss C, Hoffmann N, Morlock M. The influence of component design, bearing clearance and axial load on the squeaking characteristics of ceramic hip articulations. J Biomech 2011;44(5):837-41.

[58] Morlock M, Nassutt R, Janssen R, Willmann G, Honl M. Mismatched wear couple zirconium oxide and aluminum oxide in total hip arthroplasty. J Arthroplast 2001;16(8):1071-4.

[59] Corten K, macdonald SJ. Ceramic-on-ceramic bearings: for the hard of hearing and living alone-affirms. Semin Arthroplast 2010;21(1):24-6.

[60] Barrack RL, Burak C, Skinner HB. Concerns about ceramics in THA. Clin Orthop Relat Res 2004;429:73-9.

[61] Chevillotte C, Trousdale RT, Chen Q Guyen O, An KN. The 2009 Frank Stinchfield award: "Hip squeaking": a biomechanical study of ceramic-onceramic bearing surfaces. Clin Orthop Relat Res 2010;468(2):345-50.

[62] Yang CC, Kim RH, Dennis DA. The squeaking hip: a cause for concerndisagrees. Orthopaedics 2007;30(9):739-42.

[63] Rodriguez JA. Squeaking in total hip replacement: a cause for concern. Orthopedics 2008;31:874.

[64] Restrepo C, Matar WY, Parvizi J, Rothman RH, Hozack WJ. Natural history of squeaking after total hip arthroplasty. Clin Orthop Relat Res 2010;468 (9):2340-5.

[65] Ouenzerfi G, Massi F, Renault E, Berthier Y. Squeaking friction phenomena in ceramic hip endoprosthesis: modeling and experimental validation. Mech Syst Signal Process 2015;58-59:87-100.

[66] Fan N, Morlock MM, Bishop NE, Huber G, Hoffmann N, Ciavarella M, Chen GX, Hothan A, Witt F. The influence of stem design on critical squeaking friction with ceramic bearings. J Orthop Res 2013;31(10):1627-32.

[67] Stewart T, Tipper J, Streicher R, Ingham E, Fisher J. Long-term wear of HIPed alumina on alumina bearings for THR under microseparation conditions. J Mater Sci: Mater Med 2001;12:1053-6.

[68] Stewart TD, Tipper JL, Insley G, Streicher RM, Ingham E, Fisher J. Severe wear and fracture of zirconia heads against alumina inserts in hip simulator studies with microseparation. J. Arthroplast 2003;18(6):726-34.

[69] Hothan A, Huber G, Weiss C, Hoffmann N, Morlock M. Deformation characteristics and eigenfrequencies of press-fit acetabular cups. Clin Biomech 2011;26(1):46-51.

[70] Bishop NE, Hothan A, Morlock MM. High friction moments in large hard-onhard hip replacement bearings in conditions of poor lubrication. J Orthop Res 2013;31(5):807-13.

[71] Brockett CL, Harper P, Williams S, Isaac GH, Dwyer-Joyce RS, Jin Z, Fisher J. The influence of clearance on friction, lubrication and squeaking in large diameter metal-on-metal hip replacements. J Mater Sci: Mater Med 2008;19 (4):1575-9.

[72] Mabuchi K, Sakai R, Ota M, Ujihira M. Appropriate radial clearance of ceramic-on-ceramic total hip prostheses to realize squeeze-film lubrication. Clin Biomech 2004;19(4):362-9.
[73] Hothan A, Lewerenz K, Weiss C, Hoffmann N, Morlock M, Huber G. Vibration transfer in the ball-stem contact interface of artificial hips. Med Eng Phys 2013;35(10):1513-7.

[74] Jin ZM, Dowson D, Fisher J. Analysis of fluid film lubrication in artificial hip joint replacements with surfaces of high elastic modulus. Proc Inst Mech Eng, Part H: J Eng Med 1997;211:247-56.

[75] Hamrock BJ, Dowson D. Elastohydrodynamic lubrication of elliptical contacts for materials of low elastic modulus I - fully flooded conjunction. J Tribol $1978 ; 100(2)$.

[76] Stewart TD. Tribology of artificial joints. Orthop Trauma 2010;24(6):435-40.

[77] Higginson GR. Squeeze films between compliant solids. Wear 1978;46 (2):387-95.

[78] Jin ZM, Dowson D, Fisher J. Fluid film lubrication in natural hip joints. Tribol Ser 1993;25:545-55.

[79] Tank PW, Gest TR. Lippincott Williams and Wilkins Atlas of Anatomy. Wolters Kluwer Health/Lippincott Williams \& Wilkins; 2009.

[80] Scholes SC, Unsworth A, Goldsmith AAJ. A frictional study of total hip joint replacements. Phys Med Biol 2000;45:3721-35.

[81] Laurent MP, Pourzal R, Fischer A, Bertin KC, Jacobs JJ, Wimmer MA. In vivo wear of a squeaky alumina-on-alumina hip prosthesis: a case report. J Bone Jt Surg 2011;93(7):e27.

[82] Ranawat AS, Ranawat CS. The squeaking hip: a cause for concern-agrees. Orthopedics 2007;30:738-43.

[83] Brockett CL, Williams S, Jin Z, Isaac GH, Fisher J. Squeaking hip arthroplasties: a tribological phenomenon. J Arthroplast 2013;28(1):90-7.

[84] Sanders A, Tibbitts I, Brannon R. Concomitant evolution of wear and squeaking in dual-severity, lubricated wear testing of ceramic-on-ceramic hip prostheses. J Orthop Res 2012;30(9):1377-83.

[85] Sariali E, Jin Z, Stewart T, Fisher J. Spectral characterization of squeaking in ceramic-on-ceramic total hip arthroplasty: comparison of in vitro and in vivo values. J Orthop Res 2012;30(2):185-9.

[86] Askari E, Flores P, Dabirrahmani D, Appleyard R. A computational analysis of squeaking hip prostheses. J Comput Nonlinear Dyn 2015:024502 1-7.

[87] Kang J. The onset condition of friction noise in ball joint under concentric loading. Appl Acoust 2015;89:57-61.

[88] Glaser D, Komistek RD, Cates HE, Mahfouz MR. A non-invasive acoustic and vibration analysis technique for evaluation of hip joint conditions. J Biomech 2010;43(3):426-32.

[89] Taylor S, Manley MT, Sutton K. The role of stripe wear in causing acoustic emissions from alumina ceramic-on-ceramic bearings. J Arthroplast 2007;22 (7 Suppl 3):47-51.

[90] Glaser D, Komistek RD, Cates HE, Mahfouz MR. Clicking and squeaking: in vivo correlation of sound and separation for different bearing surfaces. J Bone Jt Surg 2008;90(Suppl 4):112-20.

[91] Dennisa DA, Komisteka RD, Northcuta EJ, Ochoac JA, Ritchiec A. "In vivo" determination of hipjoint separation and the forces generated due to impact loading conditions. J Biomech 2001;34:623-9.

[92] Komistek RD, Dennis DA, Ochoa JA, Haas BD, Hammill C. In vivo comparison of hip separation after metal-on-metal or metal-on-polyethylene total hip arthroplasty. J Bone Jt Surg 2002;84-A:1836-41.

[93] Lombardi AV, Mallory TH, Dennis DA, Komistek RD, Fada RA, Northcut EJ. An in vivo determination of total hip arthroplasty pistoning during activity. J Arthroplast 2000;15(6):702-9.

[94] Nadzadi ME, Pedersen DR, Callaghan JJ, Brown TD. Effects of acetabular component orientation on dislocation propensity for small-head-size total hip arthroplasty. Clin Biomech 2002;17:32-40.

[95] Crowninshield RD, Maloney WJ, Wentz DH, Humphrey SM, Blanchard CR. Biomechanics of large femoral heads: what they do and don't do. Clin Orthop Relat Res 2004;429:102-7.

[96] Kluess D, Martin H, Mittelmeier W, Schmitz KP, Bader R. Influence of femora head size on impingement, dislocation and stress distribution in total hip replacement. Med Eng Phys 2007;29(4):465-71.

[97] Scifert CF, Noble PC, Brown TD, Bartz RL, Kadakia N, Sugano N, Johnston RC, Pedersen DR, Callaghan JJ. Experimental and computational simulation of total hip arthroplasty dislocation. Orthop Clin N Am 2001;32:553-67.

[98] Sanders AP, Brannon RM. Assessment of the applicability of the Hertzian contact theory to edge-loaded prosthetic hip bearings. J Biomech 2011;44 (16):2802-8

[99] Mak MM, Besong AA, Jin ZM, Fisher J. Effect of microseparation on contact mechanics in ceramic-on-ceramic hip joint replacements. Proc Inst Mech Eng Part H: J Eng Med 2002;216:403-8.

[100] Elkins JM, O'Brien MK, Stroud NJ, Pedersen DR, Callaghan JJ, Brown TD. Hardon-hard total hip impingement causes extreme contact stress concentrations. Clin Orthop Relat Res 2011;469(2):454-63.

[101] Nassutt R, Wimmer MA, Schneider E, Morlock MM. The influence of resting periods on friction in the artificial hip. Clin Orthop Relat Res 2003;407:127-38.

[102] Esposito L, Tucci A. Microstructural dependence of friction and wear behaviours in low purity alumina ceramics. Wear 1997;205:88-96.

[103] Sariali E, Stewart T, Jin Z, Fisher J. Three-dimensional modeling of in vitro hip kinematics under micro-separation regime for ceramic on ceramic total hip prosthesis: an analysis of vibration and noise. J Biomech 2010;43(2):326-33.

[104] Akay A. Acoustics of friction. J Acoust Soc Am 2002;111(4):1525.

[105] Askari E, Flores P, Dabirrahmani D, Appleyard R. Nonlinear vibration and dynamics of ceramic on ceramic artificial hip joints: a spatial multibody modelling. Nonlinear Dyn 2014;76(2):1365-77. 
[106] Askari, E., Flores, P., Dabirrahmani, D., Appleyard, R., A spatial dynamic model to investigate hip squeaking and contact point in hip implants. In: Proceedings of the 11th world congress on computational mechanics (WCCM $\mathrm{XI})$, 5th European conference on computational mechanics (ECCM V), 6th European conference on computational fluid dynamics (ECFD VI). Barcelona, Spain. 2014.

[107] Hoffmann N, Fischer M, Allgaier R, Gaul L. A minimal model for studying properties of the mode-coupling type instability in friction induced oscillations. Mech Res Commun 2002;29:197-205.

[108] Kinkaid NM, O'Reilly OM, Papadopoulos P. Automotive disc brake squeal. J Sound Vib 2003;267(1):105-66.

[109] Popp K, Stelter P. Stick-slip vibrations and chaos. Philos Trans R Soc A: Math Phys Eng Sci 1990;332(1624):89-105.

[110] Currier JH, Anderson DE, Van Citters DW. A proposed mechanism for squeaking of ceramic-on-ceramic hips. Wear 2010;269(11-12):782-9.

[111] Rieker C, Köttig P, Schön R, Windler M, Wyss U. Clinical wear performance of metal on metal hip arthroplasties. In: Jacobs JJ, Craig TL, editors. Alternative bearing surfaces in total joint replacement, 1346. ASTM STP; 1998. p. 144-7.

[112] Fan N, Chen GX, Qian LM. Analysis of squeaking on ceramic hip endoprosthesis using the complex eigenvalue method. Wear 2011;271(910):2305-12.

[113] Fan N, Chen GX. Numerical study of squeaking suppresses for ceramic-onceramic hip endoprosthesis. Tribol Int 2012;48:172-81.

[114] Kang J. Theoretical model of ball joint squeak. J Sound Vib 2011;330 (22):5490-9.

[115] Weiss C, Morlock MM, Hoffmann NP. Friction induced dynamics of ball joints: Instability and post bifurcation behavior. Eur J Mech - A/Solids 2014;45:161-73.

[116] Clarke IC, Good V, Williams P, Schroeder D, Anissian L, Stark A, Oonishi H, Schuldies J, Gustafson G. Ultra-low wear rates for rigid-on-rigid bearings in total hip replacements. Proc Inst Mech Eng, Part H: J Eng Med 2000;214 (4):331-47.

[117] Clarke IC, Anissan L, Stark A, Gustafson A, Good V, Williams P, Downs B, Yu L. Comparison of M-M and M-PE hip systems at 10 million cycles in hip simulator study. In: Reiker C, Windler M, Wyss U, editors. Metasul-a metal on metal bearing. Hans Huber: Bern; 1999.

[118] Nevelos JE, Ingham E, Doyle C, Nevelos AB, Fisher J. Wear of HIPed and nonHIPed alumina-alumina hip joints under standard and severe simulator testing conditions. Biomaterials 2001;22:2191-7.

[119] Nevelos JE, Prudhommeaux F, Hamadouche M, Doyle C, Ingham E, Meunier A, Nevelos AB, Sedel L, Fisher J. Comparative analysis of two different types of alumina-alumina hip prosthesis retrieved for aseptic loosening. J Bone Jt Surg Br 2001;83-B(4):598-603.

[120] Rieker C, Konrad R, Schon R. In vitro comparison of the two hard-hard articulations for total hip replacement. Proc Inst Mech Eng Part H: J Eng Med 2001:125:153-60.

[121] Tippera JL, Hattona A, Nevelosb JE, Inghama E, Doylec C, Streicherd R, Nevelose AB, Fisher J. Alumina-alumina artificial hip joints. Part II: characterisation of the wear debris from in vitro hip joint simulations. Biomaterials 2002;23:3441-8.

[122] Firkins PJ, Tipper JL, Ingham E, Stone MH, Farrar R, Fisher J. Quantitative analysis of wear and wear debris from metal-on-metal hip prostheses tested in a physiological hip joint simulator. Biomed Mater Eng 2001;11:143-57.

[123] Al-Hajjar M, Jennings LM, Begand S, Oberbach T, Delfosse D, Fisher J. Wear of novel ceramic-on-ceramic bearings under adverse and clinically relevant hip simulator conditions. J Biomed Mater Res Part B: Appl Biomater 2013;101 (8):1456-62.

[124] Chan FW, Bobyn JD, Medley JB, Krygier JJ, Tanzer M. The Otto aufranc award. wear and lubrication of metal-on-metal hip implants. Clin Orthop Relat Res 1999;369:10-24.

[125] Goldsmith AA, Dowson D, Isaac GH, Lancaster JG. A comparative joint simulator study of the wear of metal-on-metal and alternative material combinations in hip replacements. Proc Inst Mech Eng Part H J Eng Med J 2000;214(1):39-47.

[126] Nevelos JE, Ingham E, Doyle C, Fisher J, Nevelos AB. Analysis of retrieved alumina ceramic components from Mittelmeier total hip prostheses. Biomaterials 1999;20:1833-40.

[127] Affatato S, Taddei P, Carmignato S, Modena E, Toni A. Severe damage of alumina-on-alumina hip implants: wear assessments at a microscopic level. Eur Ceram Soc 2012;32(14):3647-57.

[128] Korim M, Scholes S, Unsworth A, Power R. Retrieval analysis of alumina ceramic-on-ceramic bearing couples. Acta Orthop 2014:85(2):133-40.

[129] Reinisch G, Judmann KP, Lhotka C, Lintner F, Zweymuller KA. Retrieval study of uncemented metal-metal hip prostheses revised for early loosening. Biomaterials 2003;24:1081-91.

[130] Prudhommeaux F, Hamadouche M, Nevelos J, Doyle C, Meunier A, Sedel L. Wear of alumina-on-alumina total hip arthroplasties at a mean 11-year followup. Clin Orthop Relat Res 2000;379:113-22.

[131] Morlock MM, Bishop N, Zustin J, Hahn M, Ruther W, Amling M. Modes of implant failure after hip resurfacing: morphological and wear analysis of 267 retrieval specimens. J Bone Jt Surg 2008;90(3):89-95.

[132] Williams S, Stewart TD, Ingham E, Stone $\mathrm{MH}$, Fisher J. Metal-on-meta bearing wear with different swing phase loads. J Biomed Mater Res Part B: Appl Biomater 2004;70(2):233-9.

[133] Al-Hajjar M, Fisher J, Williams S, Tipper JL, Jennings LM. Effect of femora head size on the wear of metal on metal bearings in total hip replacements under adverse edge-loading conditions. J Biomed Mater Res Part B: Appl Biomater 2013;101(2):213-22.

[134] Saikko V, Ahlroos T, Revitzer H, Ryti O, Kuosmanen P. The effect of acetabular cup position on wear of a large-diameter metal-on-metal prosthesis studied with a hip joint simulator. Tribol Int 2013;60:70-6.

[135] Al-Hajjar M, Fisher J, Tipper JL, Williams S, Jennings LM. Wear of 36-mm BIOLOX(R) delta ceramic-on-ceramic bearing in total hip replacements under edge loading conditions. Proc Inst Mech Eng, Part H 2013;227(5):535-42.

[136] Fisher J, Al-Hajjar M, Williams S, Tipper J, Ingham E, Jennings L. (v) Simulation and measurement of wear in metal-on-metal bearings in vitro - understanding the reasons for increased wear. Orthop Trauma 2012;26 (4):253-8.

[137] Angadji A, Royle M, Collins S, Shelton J. Influence of cup orientation on the wear performance of metal-on-metal hip replacements. Proc Inst Mech Eng [H] J 2009;223:449-57.

[138] Kwon YM, Glyn-Jones S, Simpson DJ, Kamali A, McLardy-Smith P, Gill HS, Murray DW. Analysis of wear of retrieved metal-on-metal hip resurfacing implants revised due to pseudotumours. J Bone Jt Surg Br 2010;92-B(3):356-61.

[139] Leslie IJ, Williams S, Isaac G, Ingham E, Fisher J. High cup angle and microseparation increase the wear of hip surface replacements. Clin Orthop Relat Res 2009;467(9):2259-65.

[140] Nevelos JE, Ingham E, Doyle C, Nevelos AB, Fisher J. The influence of acetabular cup angle on the wear of "BIOLOX Forte" alumina ceramic bearing couples in a hip joint simulator. J Mater Sci: Mater Med 2001;12:141-4.

[141] Fisher J, Al-Hajjar M, Williams S, Jennings LM, Ingham E. In vitro measurement of wear in joint replacements: a stratified approach for enhanced reliability "SAFER" pre-clinical simulation testing. Semin Arthroplast 2012;23 (4):286-8.

[142] Nevelos J, Ingham E, Doyle C, Streicher R, Nevelos A, Walter W, Fisher J. Microseparation of the centers of alumina-alumina artificial hip joints during simulator testing produces clinically relevant wear rates and patterns. J Arthroplast 2000;15(6):793-5.

[143] Hatton A, Nevelos JE, Nevelos AA, Banks RE, Fisher J, Ingham E. Aluminaalumina artificial hip joints. Part I: a histological analysis and characterisation of wear debris by laser capture microdissection of tissues retrieved at revision. Biomaterials 2002;23(16):3429-40.

[144] Sanders AP, Brannon RM. A simple surrogate test method to rank the wear performance of prospective ceramic materials under hip prosthesis edgeloading conditions. J Biomed Mater Res Part B: Appl Biomater 2014;102 (2):311-21.

[145] Fialho JC, Fernandes PR, Eca L, Folgado J. Computational hip joint simulator for wear and heat generation. J Biomech 2007;40(11):2358-66.

[146] Liu F, Fisher J, Jin Z. Effect of motion inputs on the wear prediction of artificial hip joints. Tribol Int 2013;63:105-14.

[147] Endo Y, Renner L, Schmidt-Braekling T, Mintz DN, Boettner F. Imaging of ceramic liner fractures in total hip arthroplasty: the value of CT. Skelet Radiol 2015.

[148] Askari E, Flores P, Dabirrahmani D, Appleyard R. Study of the friction-induced vibration and contact mechanics of artificial hip joints. Tribol Int 2014;70:1-10.

[149] Dacheux C, Bocquet D, Migaud H, Girard J. Incidental discovery of an undisplaced ceramic liner fracture at total hip arthroplasty revision for squeaking. Orthop Traumatol: Surg Res 2013;99(5):631-4.

[150] Askari E, Flores P, Dabirrahmani D, Appleyard R. Planar multibody dynamic investigations of hip squeaking and ball trajectory in ceramic-on-ceramic artificial hip joints. In: Proceedings of the VII Iberian conference on tribology. Porto, Portugal: FEUP; 2013.

[151] Chevillotte C, Trousdale RT, An KN, Padgett D, Wright T. Retrieval analysis of squeaking ceramic implants: are there related specific features? Orthop Traumatol: Surg Res 2012:98(3):281-7.

[152] Buttaro MA, Zanotti G, Comba FM, Piccaluga F. Squeaking in a delta ceramicon-ceramic uncemented total hip arthroplasty. J Arthroplast 2012;27 (6):1257-9.

[153] Sariali E, Stewart T, Jin Z, Fisher J. In vitro investigation of friction under edgeloading conditions for ceramic-on-ceramic total hip prosthesis. J Orthop Res 2010;28(8):979-85.

[154] Esposito C, Walter WL, Campbell P, Roques A. Squeaking in metal-on-metal hip resurfacing arthroplasties. Clin Orthop Relat Res 2010;468(9):2333-9.

[155] Yuan Y. An eigenvalue analysis approach to brake squeal problem. In: Proceedings of the 29th ISATA conference automotive braking systems. Italy: Florence; 1996.

[156] Blajer W, Czaplicki A, Dziewiecki K, Mazur Z. Influence of selected modeling and computational issues on muscle force estimates. Multibody Syst Dyn 2010;24(4):473-92.

[157] Nikravesh PE. Computer-aided analysis of mechanical systems. Englewood Cliffs, NJ: Prentice-Hall; 1988.

[158] Ambrosio J. Rigid and flexible multibody dynamics tools for the simulation of systems subjected to contact and impact conditions. Eur J Solids A/Solids 2000;19:23-44.

[159] Cappozzo A, Gazzani F. Joint kinematic assessement during physical exercise. In: Berme N, Cappozzo A, editors. Biomechanics of human movement: applications in rehabilitation, sports and ergonomics. Worthington, Ohio: Bertec Corp.; 1990. p. 263-74.

[160] Flores P, Lankarani HM. Dynamic response of multibody systems with multiple clearance joints. J Comput Nonlinear Dyn 2012;7(3):031003-1031003-7.

[161] Flores P, Lankarani HM. Spatial rigid-multibody systems with lubricated spherical clearance joints: modeling and simulation. Nonlinear Dyn 2010;60 $(1-2): 99-114$ 
[162] Flores P, Ambrósio J, Claro JCP, Lankarani HM. Dynamics of multibody systems with spherical clearance joints. J Comput Nonlinear Dyn 2006:1(3):240.

[163] Machado M, Moreira P, Flores P, Lankarani HM. Compliant contact force models in multibody dynamics: evolution of the Hertz contact theory. Mech Mach Theory 2012;53:99-121.

[164] Lankarani HM, Nikravesh PE. A contact force model with hysteresis damping for impact analysis of multibody systems. J Mech Des 1990;112:369-76.

[165] Panovko YG, Gubanova II. Stability and oscillations of elastic systems, paradoxes, fallacies, and new concepts. New York: Consultants Bureau Enterprises; 1965.

[166] Ibrahim RA. Friction-induced vibration, chatter, squeal, and chaos. Part I: mechanics of contact and friction. Appl Mech Rev 1994;47(7):209-26.

[167] Stribeck R. The key qualites of sliding and roller bearing. Z Vereines Seutscher Jngenieure 1902;46(39):1342-8.

[168] Czichos H. Tibology - a systems approach. Amestrdam: Elsevier; 1978.

[169] Barwell FT. Tibology - a systems approach. Tribol Int 1984;17(6):299-307.

[170] Kragel'skii IV. Friction and wear. London: Butterworths; 1965.

[171] Kragel'skii IV, Dobychin MN, Kombalov VS. Friction and wear: calculation methods. Oxford: Pergamon Press; 1982.
[172] Armstrong-Helouvry B. Control of machines with friction. Dordrecht: Kluwer; 1991.

[173] Bergmann G, Deuretzbacher G, Heller M, Graichen F, Rohlmann A, Strauss J, Duda GN. Hip contact forces and gait patterns from routine activities. J Biomech 2001;34:859-71.

[174] Rieker C, Schoen R, Liebentritt G, Gnepf P, Roberts P, Grigoris P. In-vitro tribology of large metal-on-metal implants-influence of the clearance. In: Proceedings of the 50th orthopedics research society. California: San Francisco; 2004.

[175] Damm P, Dymke J, Ackermann R, Bender A, Graichen F, Halder A, Beier A Bergmann G. Friction in total hip joint prosthesis measured in vivo during walking. PLoS One 2013;8(11):1-8.

[176] Oberbach T, Begand S, Glien W, Kaddick C. Luxation test of different ceramic on ceramic couplings. Bioceramics 2007;330-332:1235-8.

[177] Begand S, Oberbach T, Glien W. Characteristic properties of a new dispersion ceramic. Bioceramics 2007:330-332:1207-10. 